\title{
Soil-Structure-Foundation Interaction Analysis of New Roller-Compacted Concrete North Lock Wall at McAlpine Locks
}

by Robert M. Ebeling, Ronald E. Wahl

U.S. Army Corps of Engineers

Waterways Experiment Station 3909 Halls Ferry Road

Vicksburg, MS 39180-6199

Final report

Approved for public release; distribution is unlimited

Prepared for U.S. Army Engineer District, Louisville P.O. Box 59

Louisville, KY 40201-0059 


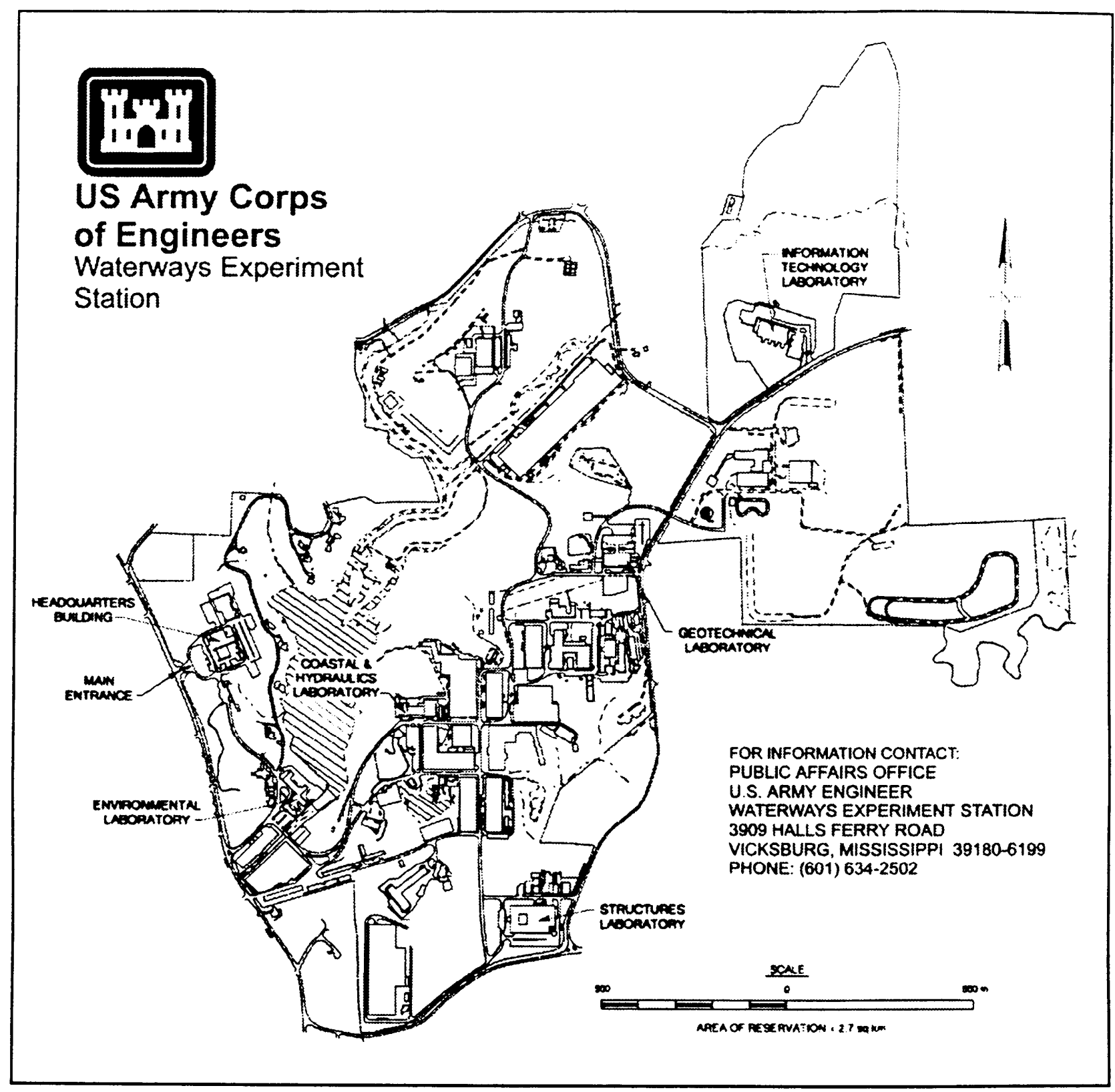

\section{Waterways Experiment Station Cataloging-in-Publication Data}

Ebeling, Robert M., 1954-

Soil-structure-foundation interaction analysis of new roller-compacted concrete, north lock wall at McAlpine Locks / by Robert M. Ebeling, Ronald E. Wahl ; prepared for U.S. Army Engineer District, Louisville.

53 p. : ill. ; $28 \mathrm{~cm}$. - (Technical report ; ITL-97-5)

Includes bibliographic references.

1. McAlpine Locks and Dam (Ky.) 2. Roller compacted concrete - Kentucky. 3. Locks (Hydraulic engineering) - Maintenance and repair - Kentucky. 4. Soil-structure interaction Kentucky. I. Wahl, Ronald E. II. United States. Army. Corps of Engineers. Louisville District. III. U.S. Army Engineer Waterways Experiment Station. IV. Information Technology Laboratory (U.S. Army Engineer Waterways Experiment Station) V. Title. VI. Series: Technical report (U.S. Army Engineer Waterways Experiment Station) ; ITL-97-5.

TA7 W34 no.ITL-97-5 


\section{Contents}

Preface $\ldots \ldots \ldots \ldots \ldots \ldots \ldots \ldots \ldots \ldots \ldots \ldots \ldots \ldots \ldots$ vi

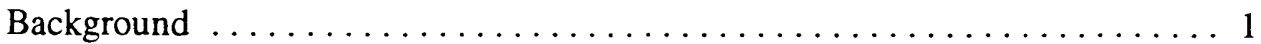

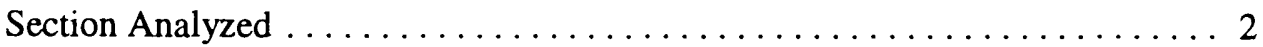

Backfill Placement Method of Analysis . . . . . . . . . . . . . . . . 2

Analysis Description .............................. 5

Soil-Structure-Foundation Interaction Analysis of New

McAlpine Lock North Wall Section . . . . . . . . . . . . . . . . . . . 6

Lock construction, backfilling, and submergence model $\ldots \ldots \ldots \ldots 6$

Finite element mesh . . . . . . . . . . . . . . . . . . . . . . . . . . 14

Material properties .................... 17

Results of Soil-Structure-Foundation Interaction Analysis of

New McAlpine Lock North Wall Section .................. 18

Effective normal and shear stress distributions computed at

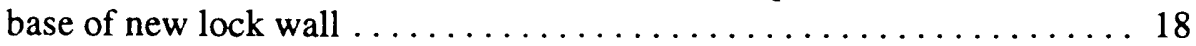

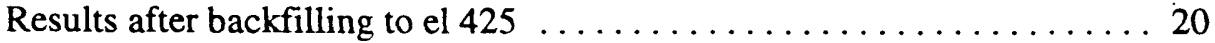

Results after partial submergence to el $395 \ldots \ldots \ldots \ldots \ldots \ldots \ldots 27$

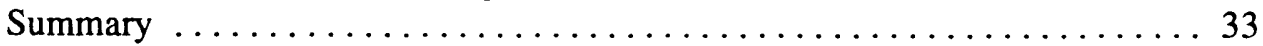

References ................................... 39

Appendix A: Backfill Placement Analysis of One-Dimensional

Soil Column . . . . . . . . . . . . . . . . . . . . . . . . . . . A1

Appendix B: Comparison of SOILSTRUCT-ALPHA Results

After Backfilling to Elevation 425 and Partial Submergence

of Backfill to Elevation 395 for Two Interface Shear Stiffness Models . . . . B1

SF 298

\section{List of Figures}

Figure 1. Typical section, north wall of new RCC McAlpine Lock ... . . 3

Figure 2. North wall of new MCC McAlpine Lock ............... 4

Figure 3. Incremental construction of RCC lock wall and incremental placement of backfill at McAlpine Lock 
Figure 4. Select load cases modeled in the finite element analyses . . . . . . 8

Figure 5. Incremental boundary water pressures applied in three load cases . . . . . . . . . . . . . . . . . . . 15

Figure 6. Finite element mesh of north wall section of new RCC McAlpine Lock

Figure 7. Effective normal stress distributions along the base of

Figure 8. Shear stress distributions along the base of new RCC lock wall . . . . . . . . . . . . . . . . . . . . . . . 23

Figure 9. Horizontal effective stress distributions along section A-A after backfilling to el $425 \ldots \ldots \ldots \ldots \ldots \ldots \ldots \ldots 24$

Figure 10. Shear stress distributions along section A-A after

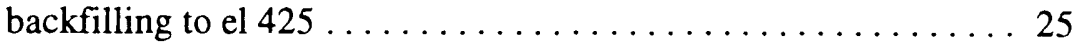

Figure 11. Variation of horizontal earth pressure coefficient, $K_{\mathrm{h}}$, with distance from heel of new RCC lock wall after

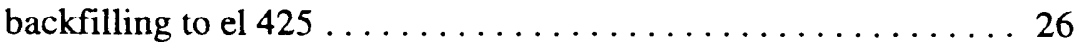

Figure 12. Variation of vertical earth pressure coefficient, $K_{v}$, with distance from heel of new RCC lock wall after backfilling to el $425 \ldots \ldots \ldots \ldots \ldots \ldots \ldots \ldots \ldots \ldots 28$

Figure 13. Planes along surfaces of the new RCC lock on which resultant forces are computed after backfill is placed to

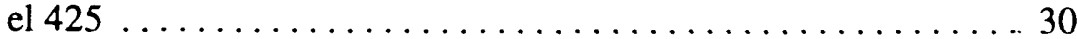

Figure 14. Horizontal effective stress distributions along section A-A .... 31

Figure 15. Shear stress distributions along section A-A $\ldots \ldots \ldots \ldots \ldots 32$

Figure 16. Variation of horizontal earth pressure coefficient, $K_{h}$, with distance from heel of new RCC lock wall after submergence to el 395 ...

Figure 17. Variation of vertical earth pressure coefficient, $K_{v}$, with distance from heel of new RCC lock wall after submergence to el 395 35

Figure 18. Planes along surfaces of the new RCC lock on which resultant forces are computed - submergence to el 395 37

Figure A1. Finite element mesh for $1-\mathrm{D}$ column analysis $\ldots \ldots \ldots \ldots \ldots$ A2

Figure B1. Two models for interface shear-stress-versus-relative-sheardisplacement behavior . . . . . . . . . . . . . . 2

Figure B2. Effective normal stress distributions along the base of new RCC lock wall - partial submergence to el 395 
Figure B3. Shear stress distributions along base of new RCC lock wall - partial submergence to el 395

Figure B4. Planes along surfaces of the new RCC lock on which

resultant forces are computed - submerged to el 396

\section{List of Tables}

Table 1. Load Step Descriptions for Construction of RCC

McAlpine Lock .................... 11

Table 2. Elastic Material Properties for 2-D Elements

Comprising SOILSTRUCT-ALPHA Finite

Element Model of New RCC McAlpine Lock . . . . . . . . . . 18

Table 3. Hyperbolic Stress-Strain and Strength Parameters

for Engineered Backfill . . . . . . . . . . . . . . . . . . . . 19

Table 4. Material Properties for the RCC-to-Limestone

Interface Elements of the SOILSTRUCT-ALPHA

Finite Element Model of McAlpine Lock . . . . . . . . . . . . . 20

Table 5. Material Properties for Interface Elements Comprising

SOILSTRUCT-ALPHA Finite Element Model of RCC

McAlipine Lock for the Backfill Placement Analysis ....... 21

Table 6. Summary of SOILSTRUCT-ALPHA Results After

Backfilling New RCC McAlpine Lock to El 425 . . . . . . . . . 27

Table 7. Summary of SOILSTRUCT-ALPHA Results After

Backfilling New RCC McAlpine Lock to El 425 . . . . . . . . . 29

Table 8. Summary of SOILSTRUCT-ALPHA Results After

Backfilling New RCC McAlpine Lock to El 425

and After Submergence to El $395 \ldots \ldots \ldots \ldots \ldots$

Table 9. Summary of SOILSTRUCT-ALPHA Results After

Backfilling New RCC McAlpine Lock to El 425 and

After Submergence to El $395 \ldots \ldots \ldots \ldots$. . . . . . . . . . 36

Table A1. Hyperbolic Stress-Strain and Strength Parameters for

Moist Backfill ....................... A3

Table A2. Material Properties for Interface Elements Comprising

SOILSTRUCT-ALPHA Finite Element Model of 1-D

Soil Column Analysis $\ldots \ldots \ldots \ldots \ldots \ldots \ldots \ldots \ldots \ldots$ 
Table B1. Summary of SOILSTRUCT-ALPHA Results Along Section A-A for "Soft" and "Stiff" Interface Shear Stiffnesses During Partial Submergence of Backfill to $\mathrm{El} 395 \ldots \ldots \ldots \ldots \ldots \ldots \ldots \ldots \ldots \ldots$. . . . . . . . . . . . . . . . . .

Table B2. Summary of SOILSTRUCT-ALPHA Results After Submergence to El 395 (Load Case 38) for "Soft" and "Stiff" Interface Shear Stiffnesses During Partial Submergence of Backfill 


\section{Preface}

This report describes the soil-to-structure-to-limestone foundation interaction analysis used to assess potential wall performance of the new roller-compacted concrete north lock wall at McAlpine Locks. Funding for this study was provided by the U.S. Army Engineer District (USAED), Louisville. Mr. Larry Dalton and Ms. Monica Greenwell, Design Branch, USAED, Louisville, were the project monitors under the general supervision of Mr. Byron McClellan, Chief, Design Branch.

This work was performed at the U.S. Army Engineer Waterways Experiment Station (WES) by Dr. Robert M. Ebeling, Computer-Aided Engineering Division (CAED), Information Technology Laboratory (ITL), and by Mr. Ronald E. Wahl, Soil and Rock Mechanics Division, Soil Research Center, Geotechnical Laboratory. Mr. John Hendricks, ITL, provided invaluable assistance in processing the results of the computer analyses and preparing the figures for this report. The authors of this report are also indebted to Mr. Kevin Abraham, ITL, for rendering his timely assistance in the development of the finite element mesh of the lock. This report was prepared by Dr. Ebeling and Mr. Wahl. Review commentary was also provided by Mr. Dalton and Ms. Greenwell. The work was accomplished under the general direction of Mr. H. Wayne Jones, Chief, CAED, ITL, and Dr. N. Radhakrishnan, Director, ITL.

At the time of the publication of this report, Director of WES was

Dr. Robert W. Whalin. Commander was COL Bruce K. Howard, EN.

The contents of this reporn are not to be used for advertising, publication, or promotional purposes. Citation of trade names does not constitute an official endorsement or approval of the use of such commercial products. 


\section{Soil-Structure-Foundation Interaction Analysis of New Roller-Compacted Concrete North Lock Wall at McAlpine Locks}

\section{Background}

A new lock is to be constructed at the McAlpine Locks on the Ohio River at Louisville, KY. The new lock chamber will be defined by rock-founded, gravity, earth-retaining monoliths. The design of these new lock walls was completed by Louisville and Portland District personnel. One of the alternatives is to construct the walls using roller-compacted concrete (RCC) with a concrete facing, with the culverts located in the floor of the lock chamber. The objective of this study was to assess the soil-to-structure-to-foundation interactions of a typical RCC lock wall two-dimensional (2-D) section.

This report describes the results of a complete soil-structure interaction (SSI) analysis of a typical section of the north wall of the new McAlpine Lock monolith using the backfill placement method of analysis incorporated in the finite element computer program SOILSTRUCT-ALPHA. SOILSTRUCT is used to understand the sometimes complex interactions among the lock, the backfill, and the foundation rock strata. The ALPHA version of SOILSTRUCT (Ebeling, Duncan, and Clough 1990) has been developed to analyze gravity lock walls like the McAlpine lock walls. 


\section{Section Analyzed}

The north wall of the new RCC McAlpine Lock is shown in Figure 1. The lock wall being analyzed is $73 \mathrm{ft}\left(22.25 \mathrm{~m}\right.$ ) high (above elevation $\left.370^{1}\right), 47 \mathrm{ft}(14.33 \mathrm{~m}$ ) wide and retains $55 \mathrm{ft}(21 \mathrm{~m})$ of well-compacted, dense granular back-fill. The base of the new lock (at el 370 ) is $9.5 \mathrm{ft}(2.9 \mathrm{~m}$ ) above the floor of the new lock chamber. The postconstruction water table in the backfill is assigned el 395, and the pool elevation is at el 383 in the complete SSI analysis. The section analyzed is representative of the north wall of the new lock at station $25+00$. The complete 2-D section modeled in the analysis is shown in Figure 2. The section includes two of the existing lock walls, the existing backfill and shale foundation between these two locks, and a significant portion of the limestone foundation. The 2-D section was terminated at the center line of the existing McAlpine Lock and the center line of the new lock.

\section{Backfill Placement Method of Analysis}

One of the earliest successful applications of soil-structure interaction analysis was performed by Clough and Duncan (1969) in their analysis of the two reinforced-concrete U-frame locks at Port Allen and Old River. These two locks had been extensively instrumented. Prior to Clough and Duncan's analysis, the instrumentation data had been thought to be unreliable and contrary to the perceived understanding of the behavior of locks to loadings encountered during lock operation. Clough and Duncan's study showed that the best agreement between results computed using the finite element method and those obtained through instrumentation measurements is obtained when the actual construction process is simulated as closely as possible in the analysis. During their study, Clough and Duncan developed what is referred to as a backfill placement analysis in which the loads exerted by the backfill on the lock wall are generated automatically during simulated placement of backfill behind the wall (i.e., predetermined earth pressure force distributions between the soil and the lock are not specified). This requires that the soil backfill and foundation soil strata be included in the finite element mesh. This procedure involved the use of incremental finite element analysis with nonlinear, stress-dependent, stress-strain behavior for the soil. Linear elastic behavior was assumed for the concrete lock wall. An additional requirement is that interface elements be incorporated within the finite element mesh to allow for relative movement between the soil and structure. Since the Clough and Duncan study, soil-structure interaction analysis using the backfill placement procedure has been successfully applied to a variety of earth retaining structures. An extensive database of strength and hyperbolic stress-strain parameters (using data obtained from consolidated-drained triaxial tests on a variety of soils) has also evolved because of the extensive number of applications of this family of numerical procedures in engineering practice (see discussion in Ebeling and Mosher 1996). An updated version of SOILSTRUCT, referred to as SOILSTRUCT-ALPHA, is used in this study.

\footnotetext{
1 All elevations (el) cited herein are in feet referenced to the National Geodetic Vertical Datum.
} 


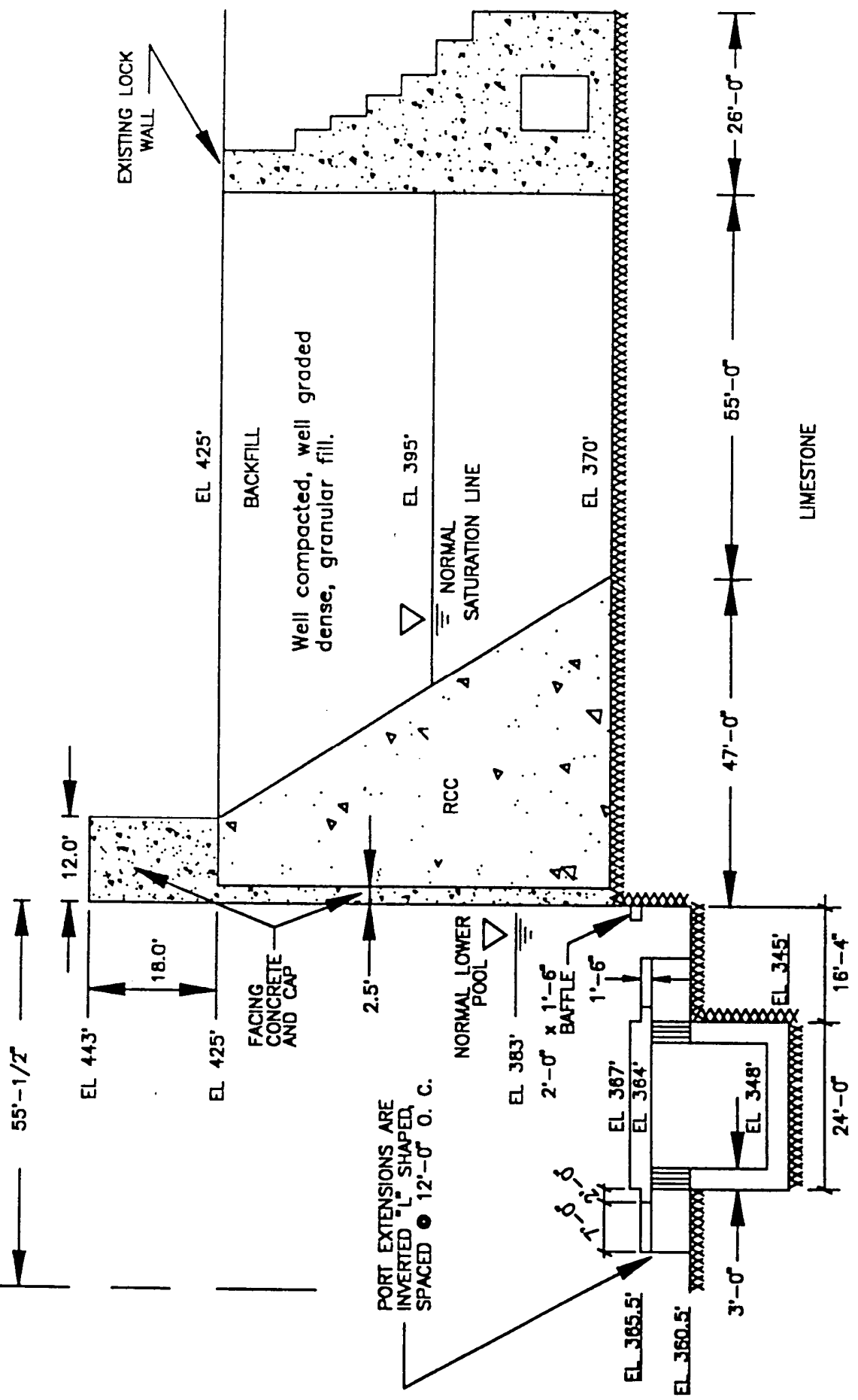

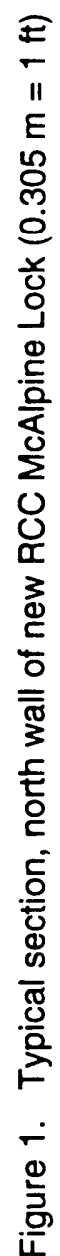




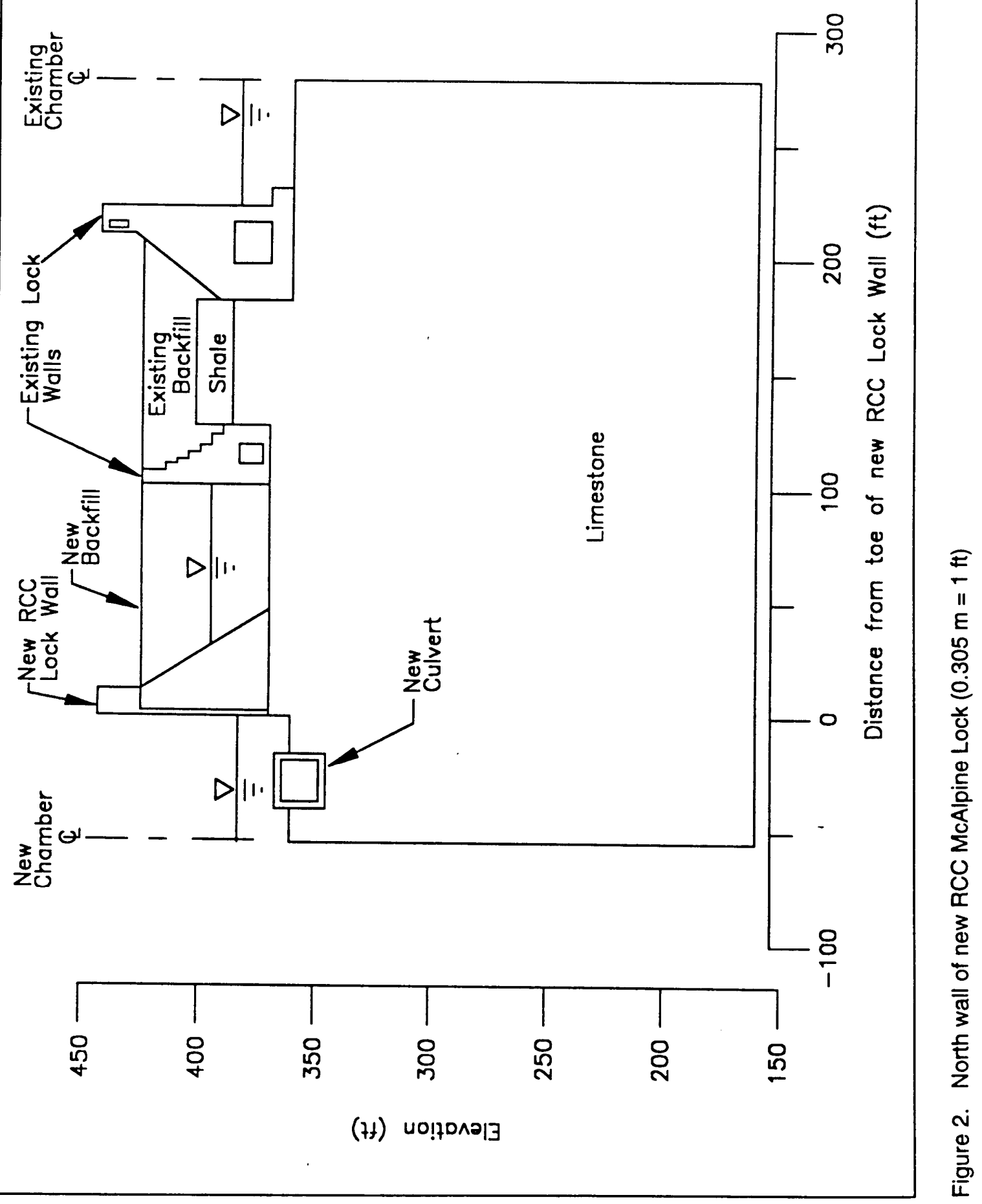




\section{Analysis Description}

SOILSTRUCT-ALPHA (Ebeling, Duncan, and Clough 1990) is a specialpurpose, finite element program for 2-D, plane strain analysis of soil-structure interaction problems. SOILSTRUCT calculates displacements and stresses resulting from incremental construction, backfilling, excavation, dewatering, rising water table, and/or load application. Nonlinear, stress-path-dependent, stress-strain behavior of the backfill was approximated in the finite element analysis using the tangent modulus method. In the tangent modulus method, new values of tangent moduli are assigned to each soil element at each increment of loading (i.e., dewatering, lock construction, and backfilling) or unloading (i.e., excavation, rising water table). The modulus values assigned to each element are adjusted in accordance with their stresses to simulate nonlinear behavior.

SOILSTRUCT was expanded during the U.S. Corps of Engineers' first Repair, Evaluation, Maintenance, and Rehabilitation (REMR) Research Program to model the loss of contact between the base of a wall (a lock in this case) and its rock foundation using a procedure called the ALPHA method (Ebeling, Duncan, and Clough 1990; Ebeling et al. 1992). The ALPHA method was extended to soil elements by Regalado, Duncan, and Clough (1992) to reduce numerical inaccuracies in soil elements that are at or near failure.

Another enhancement contained within this version of SOILSTRUCT is the reintroduction of the hyperbolic shear-stress displacement relationship for the interface element. Although present in the original version of SOILSTRUCT (Clough and Duncan 1969), this nonlinear relationship was missing from the version of computer code in which the alpha method was incorporated.

The continua elements used to model the soil and the soil-to-structure interface elements which may have failed in shear at one stage of loading have the ability to recover their shear stiffness and shearing resistance as a result of an increase in confining pressures at some later stage of loading in this version of SOILSTRUCTALPHA. Several other improvements have been made to the material models and to the numerical procedures implemented within SOLSTRUCT-ALPHA based on experience gained at the U.S. Army Engineer Waterways Experiment Station (WES) in conducting SSI analyses of different types of Corps structures.

In summary, the ALPHA version of SOILSTRUCT used on this project contains numerous improvements to the analytical procedures used for modeling various aspects of features impacting the SSI of lock walls. Several of these features are deemed by the authors of this report to be critical to an accurate assessment of the SSI of the north wall section of the new McAlpine Lock. 


\section{Soil-Structure-Foundation Interaction Analysis of New McAlpine Lock North Wall Section}

\section{Lock construction, backfilling, and submergence model}

Project engineers at the Louisville District established that the probable scheduling of construction of the new lock is placement of a $1.5-\mathrm{ft}-(0.46-\mathrm{m}-)$ thick layer of RCC followed by placement of backfill to the top of the newly placed RCC lift. Each layer of RCC possesses sufficient stiffness at the time of placement to support construction equipment. This staged (incremental) construction proceeds until the final elevations (Figure 3) are reached on the new lock and backfill. Incremental construction of the RCC and placement of the backfill behind the wall is staggered by one lift in the SOILSTRUCT-ALPHA incremental construction/backfill placement analysis. This altered construction schedule in the analysis results in a "stiffer" layer of RCC elements being in place, adjacent to the newly placed layer of soil. Thus, the conditions in the field are modeled in the finite element analysis. The stages of loading used in the SOILSTRUCT-ALPHA analysis are described in the following paragraphs.

The complete SSI of the north wall of the new McAlpine Lock cross section (Figure 2) is modeled in three phases. The first phase of the analysis introduces the self-weight of the existing locks and existing backfill to the shale and limestone foundation. This is accomplished using the gravity turn-on option in SOILSTRUCT-ALPHA prior to construction of the new lock and placement of new backfill. This initial phase is illustrated in Figure 4a for load case "I." The second phase models the incremental construction of the RCC lock wall and the incremental placement of the (moist) backfill behind the wall. The third phase of the SSI analysis models the postconstruction, partial submergence of the site. Table 1 lists the initial stage of loading and each of the subsequent 38 stages of loading in the SSI analysis of the north wall section of the new McAlpine Lock.

The incremental construction of the RCC lock wall is modeled in the first 24 load cases (following the gravity turn-on analysis), with the incremental placement of the moist backfill during 22 of these load increments. Figure 3 shows the thickness of the layers of RCC and backfill that are used in this second phase of the analysis. The thickness of the layers range from $1.5 \mathrm{ft}(0.46 \mathrm{~m})$ thick at the bottom to $5 \mathrm{ft}(1.5 \mathrm{~m})$ thick at the top. Placement of the first $1.5-\mathrm{ft}-$ $(0.46-\mathrm{m})$ thick layer of RCC of the new lock wall precedes the placement of the first layer of backfill in the SOILSTRUCT-ALPHA analysis, labeled load case 1 in Table 1 and in Figure 4a. This allows the first layer of RCC to "stiffen" prior to the placement of the adjacent backfill layer in the analysis. The second load case models placement of the first 1.5 -ft-thick layer of moist backfill, labeled load case 2 in Table 1 and shown in Figure 4a. The second, "soft" 1.5-ft- (0.46-m) thick layer of RCC is also placed to el 373 in load case 2 to expedite the analysis (and without compromising accuracy). Incremental construction of the next layer of "softer" RCC layer precedes the placement of the next layer of backfill by one 


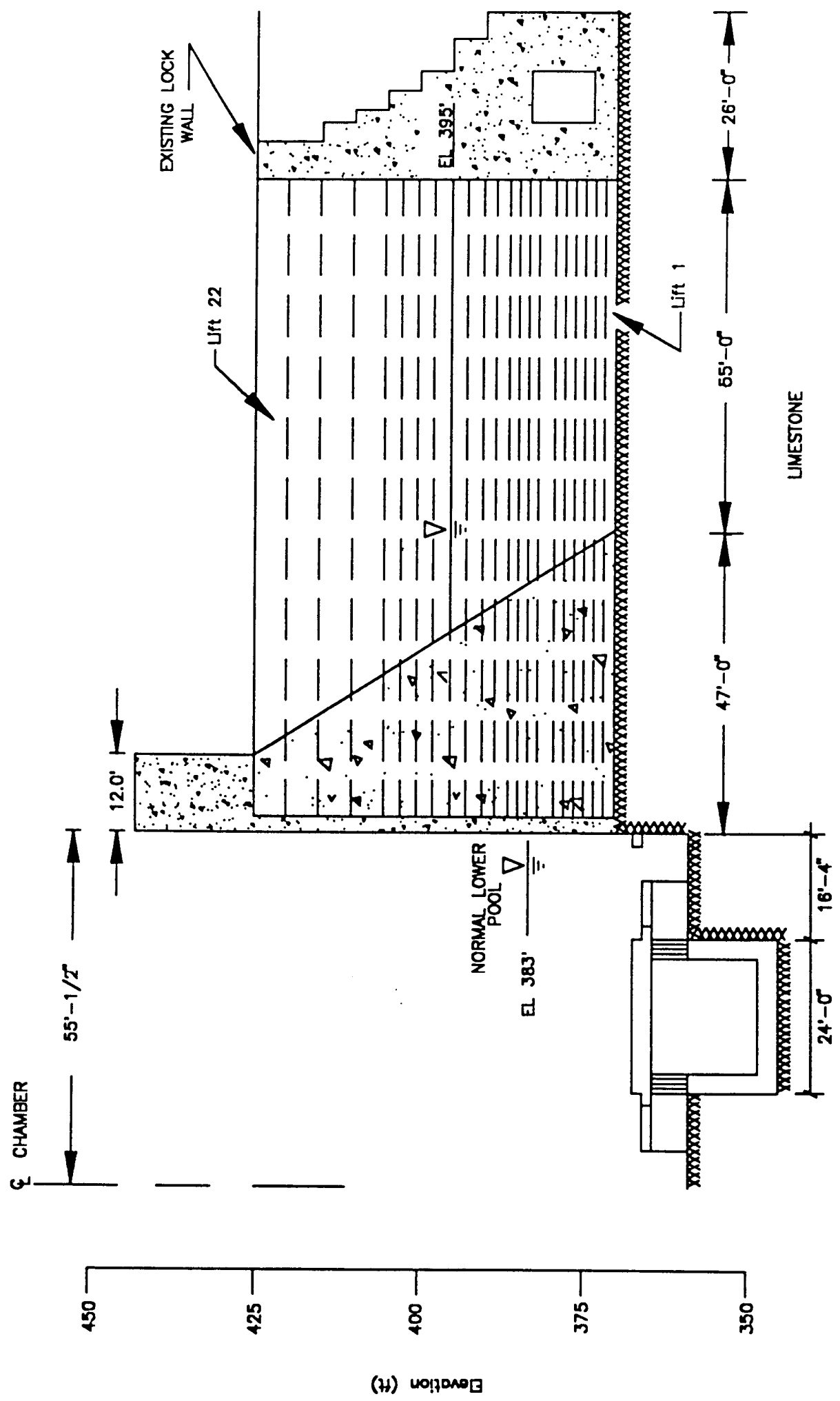



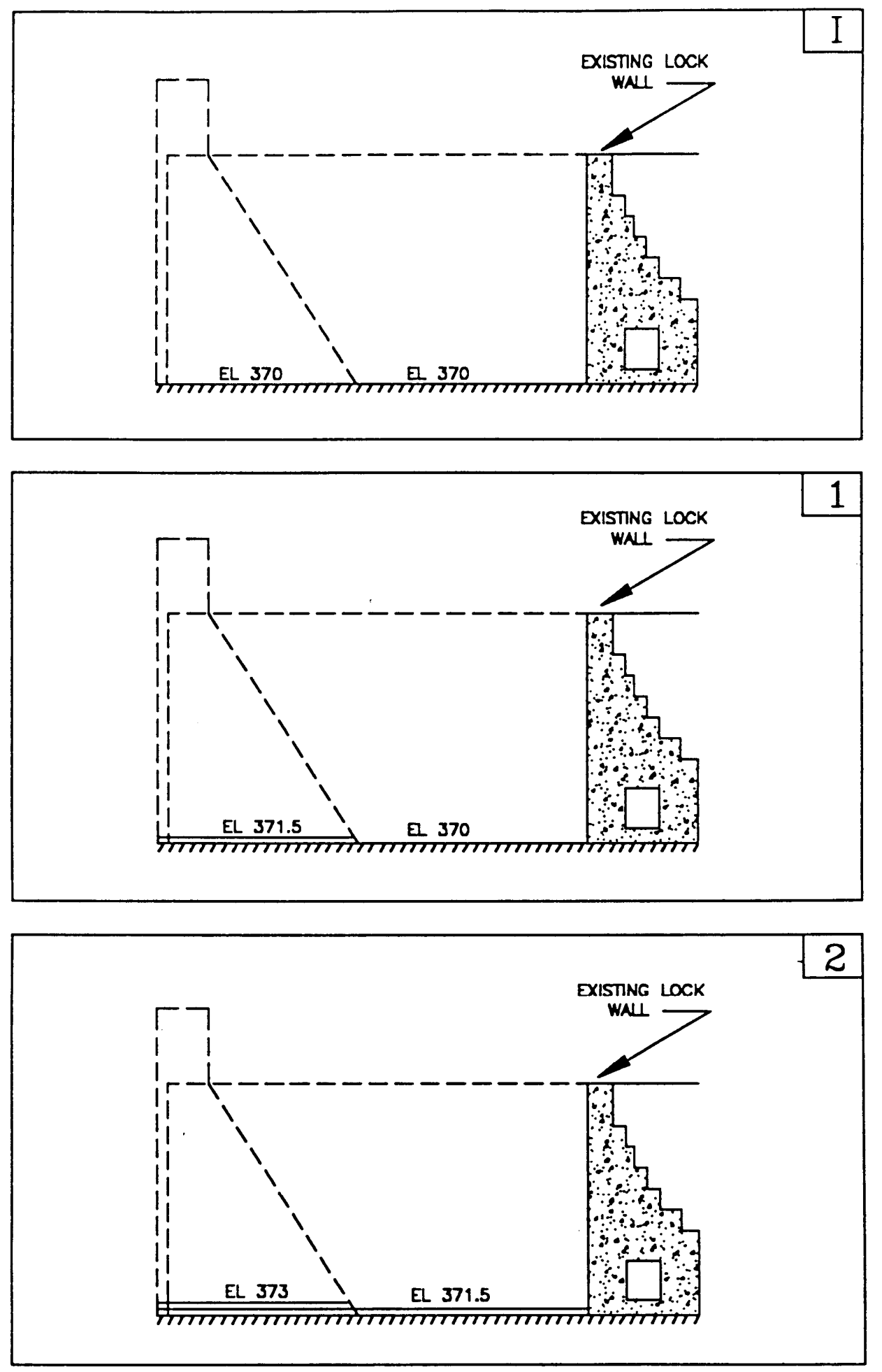

a. Load cases 1, 2, and 3

Figure 4. Select load cases modeled in the finite element analyses (Sheet 1 of 3 ) 

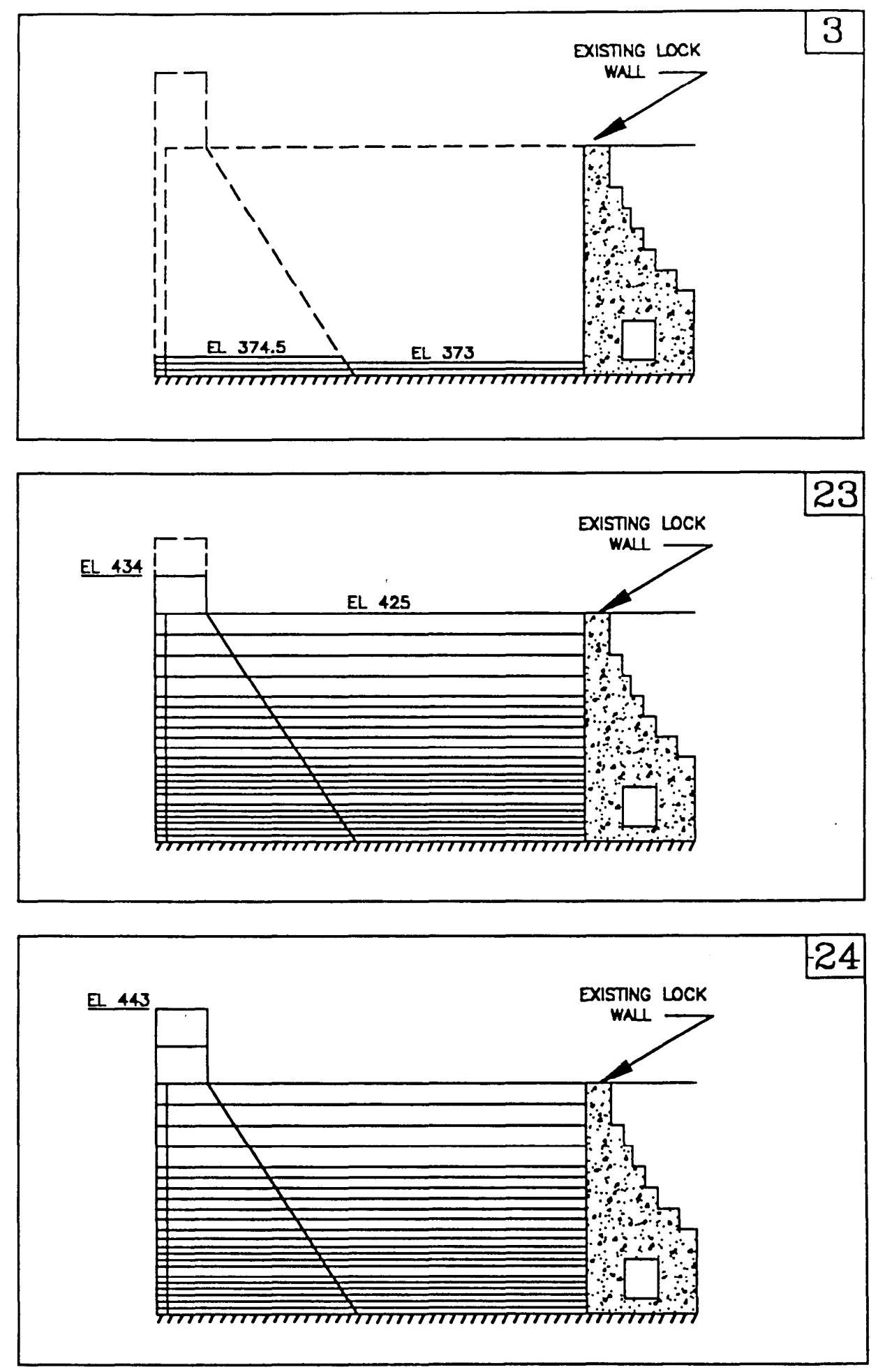

b. Load cases 3,23 , and 24

Figure 4. (Sheet 2 of 3) 

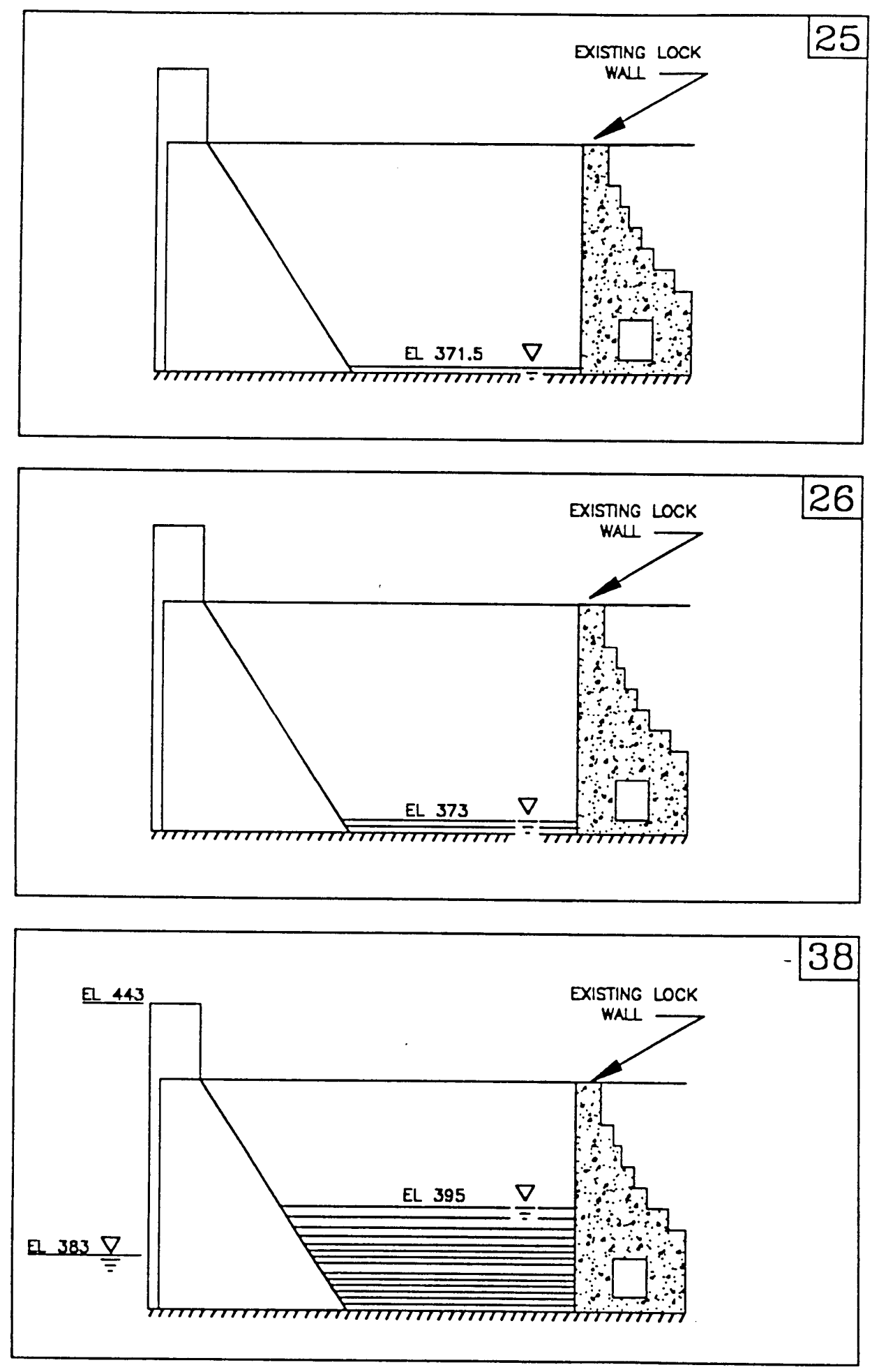

c. Load cases 25,26 , and 38

Figure 4. (Sheet 3 of 3) 


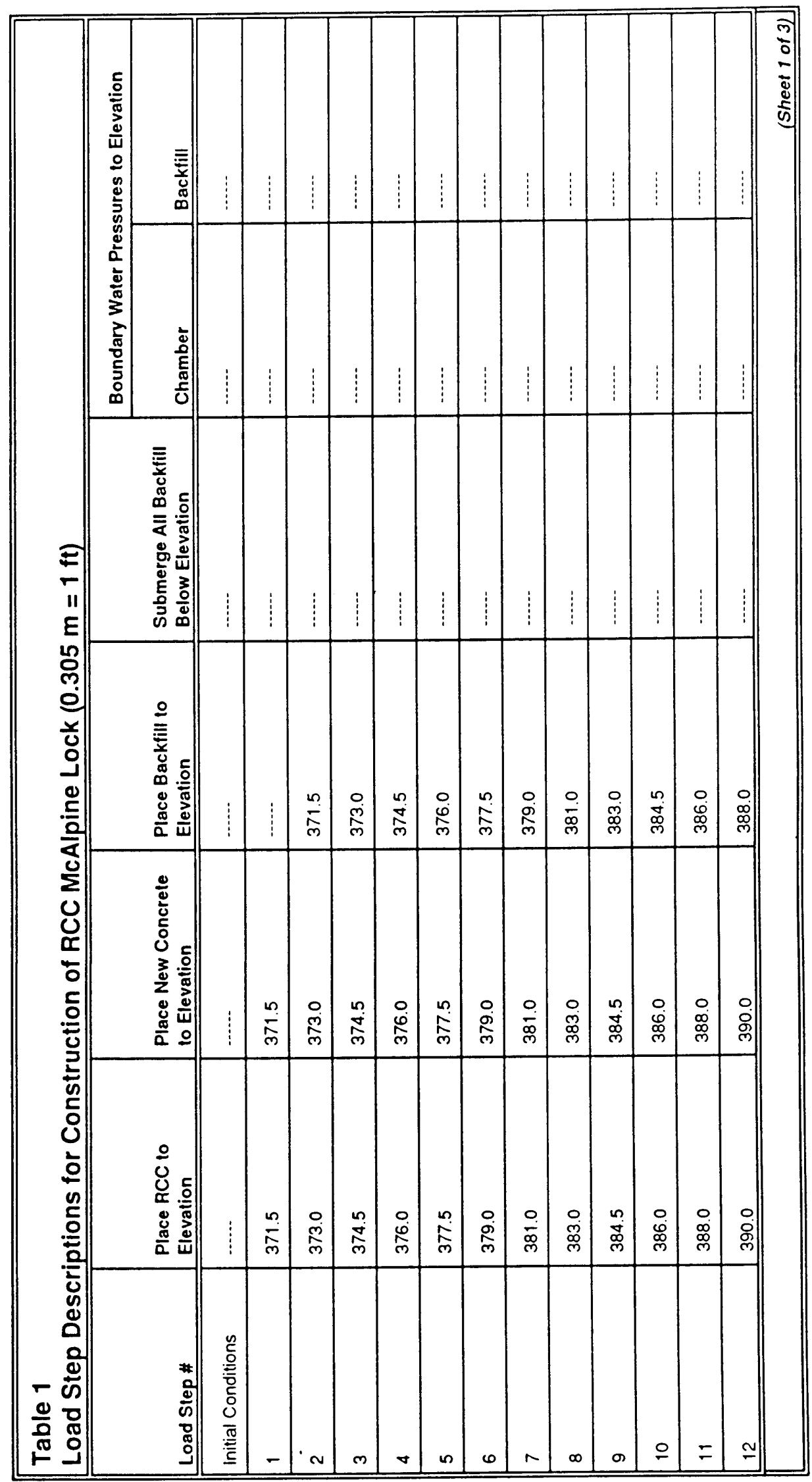




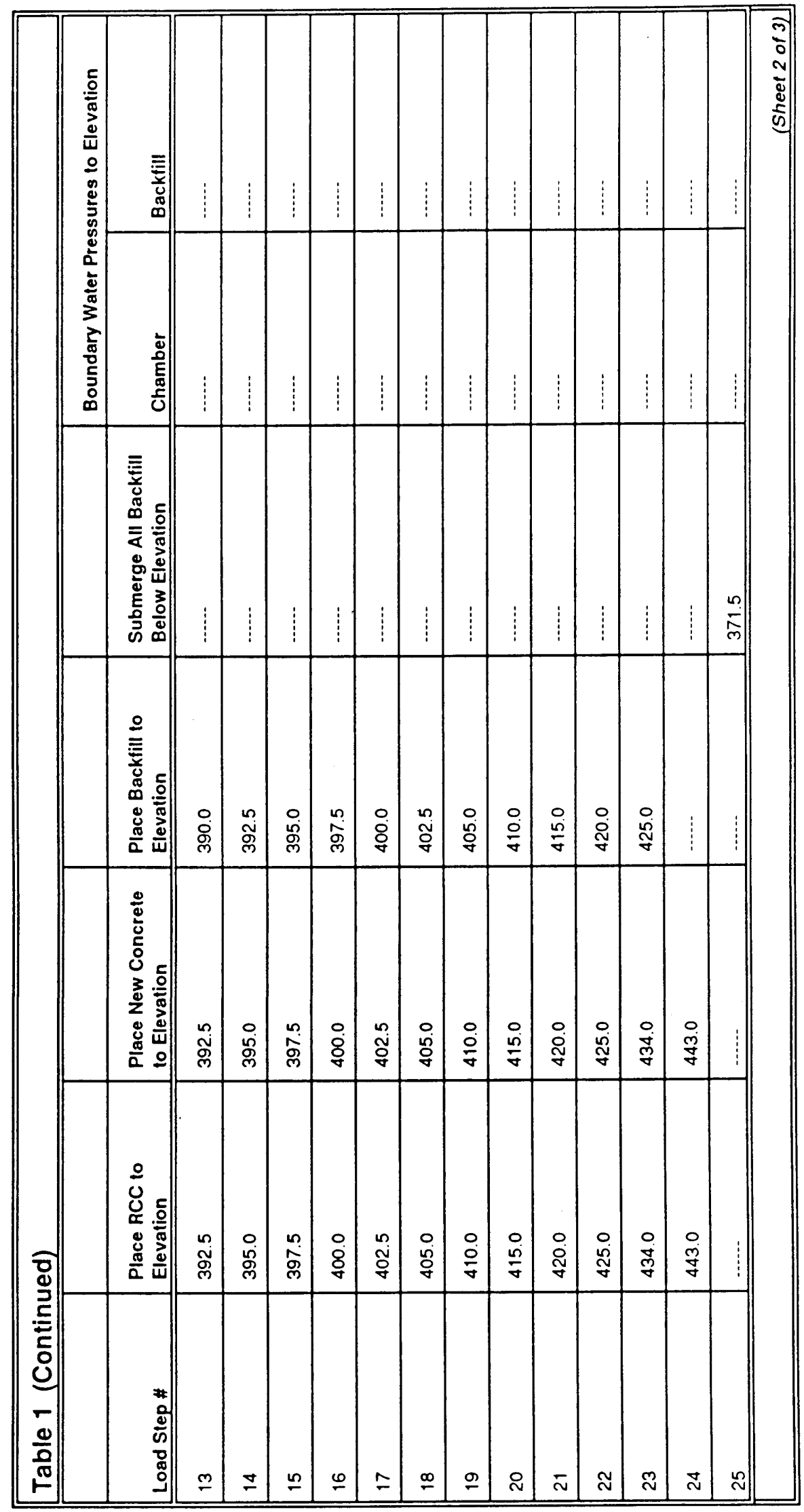




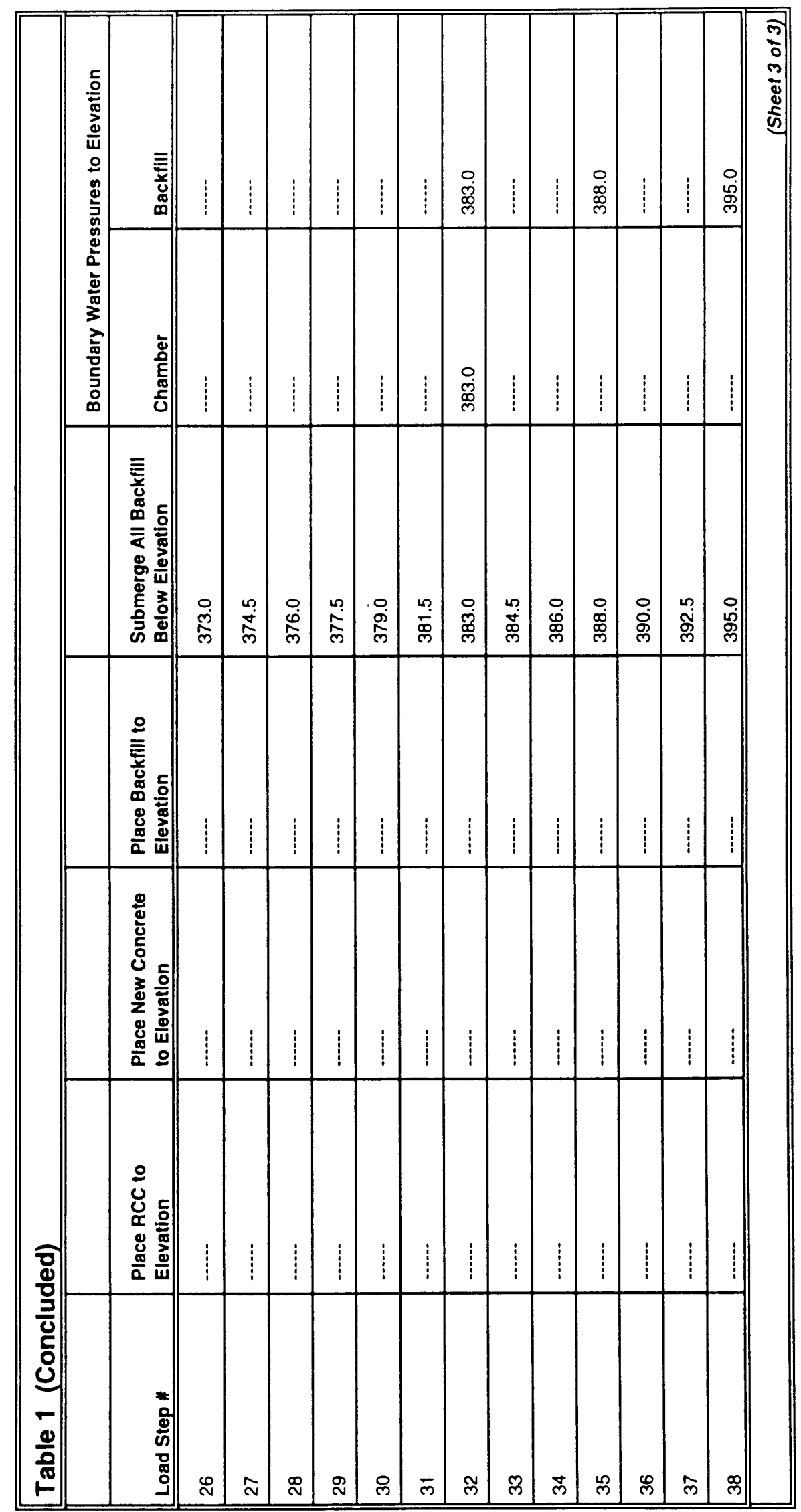


lift throughout the analysis (as shown in Figures $4 \mathrm{a}$ and $4 \mathrm{~b}$, and Table 1). This allows SOILSTRUCT-ALPHA to account for the stiffer RCC immediately adjacent to the newly placed layer of backfill. Incremental placement of the backfill to el 425 concludes with load case 23 , and incremental construction of the lock concludes with load case 24 (Figure $4 b$ ).

The third phase of SSI analysis models the postconstruction, partial submergence of the site and is accomplished using SOILSTRUCT-ALPHA in 14 load cases. The water table in the existing and new lock chambers is raised incrementally to el 383 , and the water table in the new backfill is raised incrementally to el 395 (listed as load cases 25 through 38 in Table 1). A hydrostatic water table is assumed for the backfill in all load cases. Loadings consist of buoyancy forces acting within the newly placed backfill and boundary water pressures acting normal to both faces and base of the new RCC lock, the limestone foundation, and the faces of the two existing lock walls. A linear (uplift) pore water pressure distribution is applied along the new RCC lock-tolimestone foundation interface, with the uplift (pressure) heads set equal to $13 \mathrm{ft}$ $(3.96 \mathrm{~m})$ below the toe and $25 \mathrm{ft}(7.6 \mathrm{~m})$ below the heel of the wall.

Figure $4 \mathrm{c}$ shows the incremental submergence of the backfill for load cases 25 and 26 and for the final load case of 38 . The partial submergence of the site is accomplished in the finite element model using two features in SOILSTRUCTALPHA: application of buoyancy forces to the submerged backfill and application of boundary water pressures along the faces of impermeable materials (i.e., all locks and the foundation). The buoyancy loads acting on the submerged soil elements are applied using the SEEP option in SOILSTRUCT. This subroutine is modified for this analysis to account for the difference between the submerged and moist unit weights for the soil. The water table is raised in the newly placed backfill in the last 14 load increments (Table 1). Water pressures acting normal to both faces and base of the new RCC lock, the limestone foundation, and the faces of the two existing lock walls are applied incrementally in load cases 32, 35, and 38, as shown in Figure 5. The interface elements used to model the RCC lock-to-limestone interface allow for the application of pore water pressures directed upward along the base of the new RCC lock and boundary water pressures directed downward along the top face of the limestone interface region. This distribution of pore water pressure corresponds to the nonsite-specific uplift pressure distributions recommended for the design of new locks (Headquarters, Department of the Army 1995) and is consistent with steady-state confined flow along a joint of constant aperture (Ebeling and Pace 1996, 1997).

\section{Finite element mesh}

Figure 6 shows the finite element mesh of the Figure 2 cross section of the north wall of the new lock. The mesh comprises 3,784 nodal points and 3,634 continua and 162 interface elements. Of the 3,634 continua elements, 468 model new RCC lock and concrete facing, 2,154 model the limestone and shale foundation, and 550 model the new backfill. The remaining 462 continua 

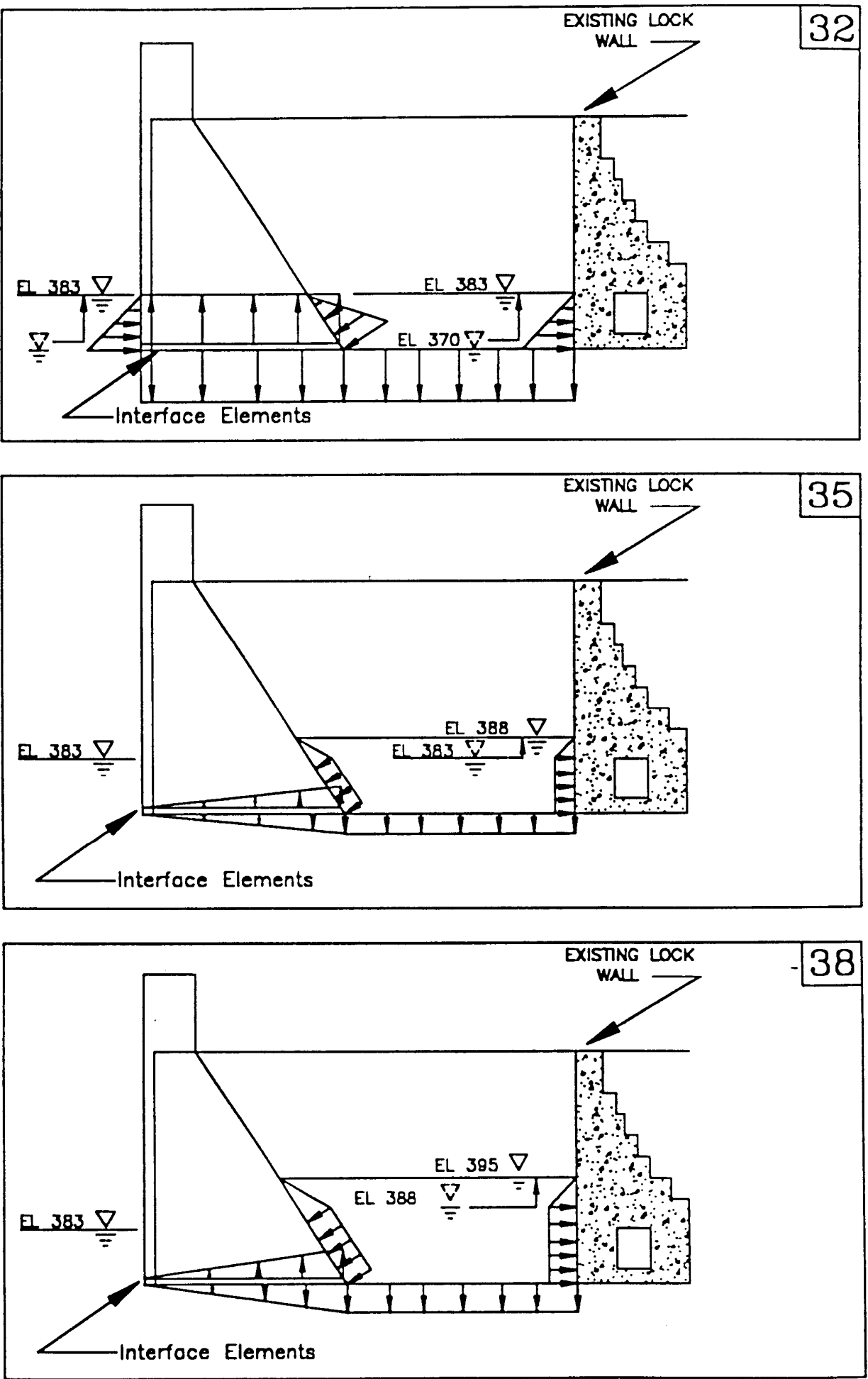

Figure 5. Incremental boundary water pressures applied in three load cases $(0.305 \mathrm{~m}=1 \mathrm{ft})$ 


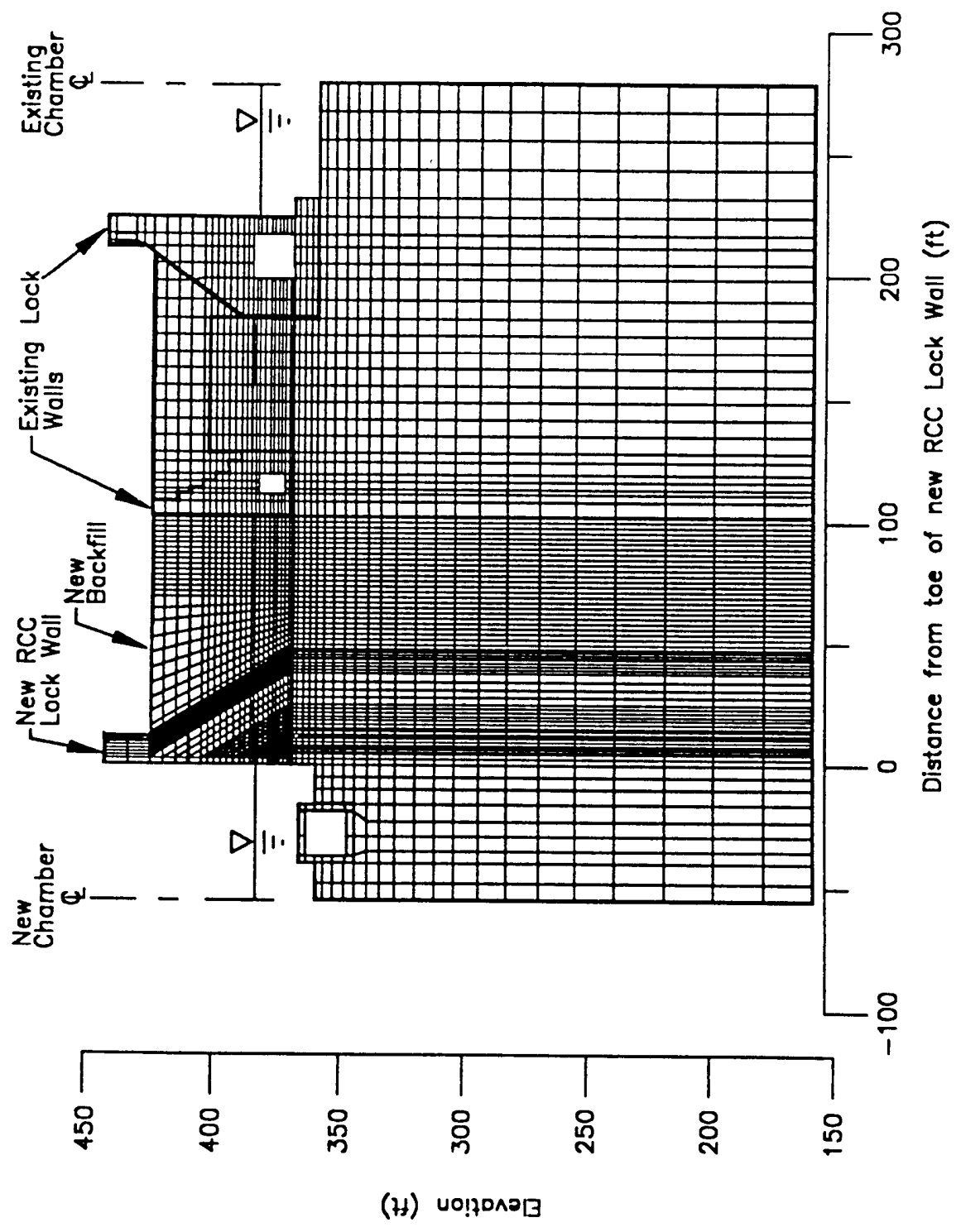

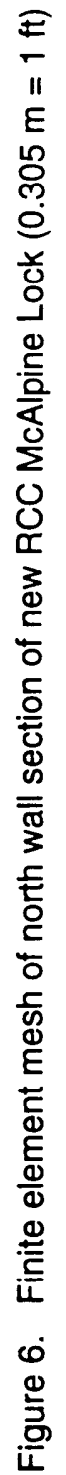


elements represent the two existing locks and the existing backfill between these locks. Of the 162 interface elements, 30 model the new RCC lock-to-limestone foundation interface, 25 model the limestone-to-new backfill interface, 22 model the new RCC lock-to-new backfill interface, and 22 model the existing lock-tonew backfill interface. Forty-six of the remaining interface elements are in the limestone foundation along two vertical planes, each extending through the limestone foundation from the heel of the new RCC lock wall and from the existing lock wall, respectively. These 46 interface elements are "locked" together with the assignment of high normal and shear stiffnesses. The remaining 17 interface elements extend along el 370 from the front face of the existing center lock wall, to the culvert of the existing, operational lock wall and are locked together with high normal and shear stiffnesses.

\section{Material properties}

Table 2 lists the values assigned to the elastic parameters of the RCC, the concrete facing for the new lock, the concrete of the existing locks, and the limestone and shale foundation. The elastic parameters assigned to the RCC are based upon data obtained for the RCC mixture used on the Willow Creek Dam project and provided by Portland District personnel. The soil that comprises the backfill for the new RCC lock will be a well-compacted, well-graded, dense granular backfill. Moist and saturated unit weights equal $126 \mathrm{pcf}$ $\left(2,018.33 \mathrm{~kg} / \mathrm{m}^{3}\right)$ and $130 \mathrm{pcf}\left(2,082.39 \mathrm{~kg} / \mathrm{m}^{3}\right)$, respectively. Site-specific triaxial test data are unavailable for the backfill. Material parameters are assigned in the finite element analysis based on empirical correlations to the results for similar types of soils (and with the same density) for which hyperbolic stressstrain curve material parameters are available (e.g., Duncan et al. 1978). An additional requirement for the soil model was that the assigned soil properties correspond to an at-rest earth pressure coefficient $K_{o}$ equal to 0.44 , based on the Jaky equation for $\mathrm{K}_{\mathrm{o}}\left[=1-\sin \phi^{\prime}\right]$ with $\phi^{\prime}$ equal to $34 \mathrm{deg}$. Appendix A describes the calculations made that result in the assignment of values for the hyperbolic stress-strain soil model of the backfill given in Table 3. These calculations include a settlement analysis made using SOILSTRUCT-ALPHA of a 55-ft(16.76-m) high, one-dimensional (1-D) soil column due to self-weight of the moist soil.

Similarly, no specific tests are performed to define the hyperbolic shear stressrelative displacement relationship for the interface element used in SOILSTRUCT-ALPHA. The assignment of material parameters to the interface elements are based on empirical correlations to interfaces having similar types of soils (and with the same density) for which hyperbolic stress-strain curve material parameters are available (e.g., Clough and Duncan 1969, and Peterson et al.

1976). Table 4 summarizes the interface model and strength parameters assigned to the RCC lock-to-limestone foundation. Zero tensile strength is assumed for the material comprising the RCC lock-to-limestone foundation interface in this analysis. Table 5 summarizes the material properties assigned to the interfaces between the RCC-to-backfill, the limestone-to-backfill, and the existing lock wall concrete-to-backfill regions. 


\begin{tabular}{|c|c|c|c|}
\hline \multicolumn{4}{|c|}{$\begin{array}{l}\text { Table } 2 \\
\text { Elastic Material Properties for 2-D Elements Comprising } \\
\text { SOILSTRUCT-ALPHA Finite Element Model of New RCC McAlpine } \\
\text { Lock }\left(0.517 \mathrm{kN} / \mathrm{m}^{3}=1 \mathrm{pcf}, 6.894 \mathrm{psi}=1 \mathrm{kPa}\right)\end{array}$} \\
\hline Material Type & Unit Weight, pef & E,psi & $\mathbf{v}$ \\
\hline $\mathrm{RCC}$ & 150 & $2,000,000$ & 0.21 \\
\hline Concrete Face & 145 & $3,400,000$ & 0.15 \\
\hline Existing Concrete & 145 & $3,400,000$ & 0.15 \\
\hline Limestone & -- & $5,000,000$ & 0.25 \\
\hline Shale & -- & $3,000,000$ & 0.25 \\
\hline
\end{tabular}

During the postconstruction partial submergence of the backfill to el 395 (identified as load cases 25 through 38 in Table 1), the buoyancy forces act upward, unloading the backfill. This results in a reversal in the direction of the applied shear stress increment or, equivalently, unloading of both the new RCC lock-to-backfill interface elements and the existing lock concrete-to-backfill interface elements. Interface tests reported in Peterson et al. (1976) show that the interface elements follow a steeper shear stress versus relative shear displacement curve than that described by the "primary" hyperbolic loading curve (the tangent shear stiffness $\mathrm{k}_{\mathrm{st}}=\mathrm{k}_{\mathrm{si}}\left[1-\mathrm{R}_{\mathrm{fi}} \mathrm{SL}\right]^{2}$ ). To model this behavior, the interface model parameter $R_{\mathrm{fi}}$ is set equal to zero for these interface elements during unloading. This eliminates the "shear softening" while maintaining the influence of the effective normal stress on the value of the tangent shear stiffness $\mathrm{k}_{\mathrm{st}}$ by means of the term $\mathrm{k}_{\mathrm{si}}$ (Table 4). This concept is discussed further in Appendix B.

\section{Results of Soil-Structure-Foundation Interaction Analysis of New McAlpine Lock North Wall Section}

Following the gravity turn-on analysis, the incremental construction of the $\mathrm{RCC}$ lock wall and placement of moist backfill is modeled in the first 24 load cases for the finite element model of the McAlpine lock shown in Figure 6. This is followed by the postconstruction, partial submergence of the site in 14 load cases. The results of this complete SSI analysis follow.

\section{Effective normal and shear stress distributions computed at base of new lock wall}

Figures 7 and 8 show the resulting effective normal and shear stress distributions along the RCC lock-to-limestone interface after construction of the new lock and backfilling to el 425 (load case 24). Both effective normal and shear 


\section{Table 3}

Hyperbolic Stress-Strain and Strength Parameters for Engineered Backfill

$\left(0.157 \mathrm{kN} / \mathrm{m}^{3}=1 \mathrm{pcf}, 47.88 \mathrm{~Pa}=1 \mathrm{psf}\right)$

\begin{tabular}{|c|c|c|c|c|c|c|c|c|c|c|c|}
\hline \multirow[b]{2}{*}{ Backfill } & \multirow[b]{2}{*}{$\begin{array}{l}\text { Unit Weight, } \\
\text { psf }\end{array}$} & \multicolumn{2}{|c|}{$\begin{array}{l}\text { Strength } \\
\text { Parameters }\end{array}$} & \multirow[b]{2}{*}{$K_{\circ}$} & \multicolumn{7}{|c|}{ Hyperbolic Parameters } \\
\hline & & $c^{\prime}, p s f$ & $\phi^{\prime}$, deg & & K & $n$ & $\mathrm{~K}_{\mathrm{UR}}$ & $\mathrm{K}_{\mathrm{o}}$ & m & $V_{\text {nom }}$ & $\mathbf{R}_{\mathrm{F}}$ \\
\hline $\begin{array}{l}\text { Moist } \\
\text { Granular } \\
\text { Backfill }\end{array}$ & 126 & 0 & 34 & 0.44 & 500 & 0.5 & 1000 & 175 & 0.5 & 0.025 & 0.7 \\
\hline $\begin{array}{l}\text { Submerged } \\
\text { Granular } \\
\text { Backfill }\end{array}$ & 130 & 0 & 34 & 0.44 & 500 & 0.5 & 1000 & 175 & 0.5 & 0.025 & 0.7 \\
\hline
\end{tabular}

Note:

$K_{o}$ by Jaky $=1-\sin \phi^{\prime}$

Tangent Modulus, $E_{t}=E_{i}\left(1-R_{F} S L\right)^{2}$

Initial Modulus, $E_{i}=K P_{a}\left(\frac{\sigma_{3}^{\prime}}{P_{a}}\right)^{n}$

Stress Level, SL $=\left(\sigma_{1}-\sigma_{3}\right) /\left(\sigma_{1}-\sigma_{3}\right)_{\text {Failure }}$

$\left(\sigma_{1}-\sigma_{3}\right)_{\text {Failure }}=\frac{2 c \cos \phi+2 \sigma_{3}^{\prime} \sin \phi}{1-\sin \phi}$

Unload Reload Modulus, $E_{U R}=K_{U R} P_{a}\left(\frac{\sigma_{3}}{P_{a}}\right)^{n}$

Bulk Modulus, $B=\frac{E_{i}}{\left(3-6 v_{\text {nom }}\right)}$

Bulk Modulus, $B=K_{B} P_{\cdot}\left(\frac{o_{3}}{P_{A}}\right)^{m}$

$v_{\text {nom }}=$ Nominal value of Poissoris ratio

Poissor's ratio, $v=\frac{1}{2}\left[1-\left[\left(1-2 v_{\text {nom }}\right)\left(1-R_{F} S L\right)^{2}\right]\right]$

$P_{A}=$ atmospheric pressure

computed below the toe of the new RCC lock $(x=0 \mathrm{ft})$ because the greatest concrete mass is concentrated above this region and because of the overturning moment about the toe resulting from the $55 \mathrm{ft}(16.76 \mathrm{~m})$ of backfill. The effective normal 


\begin{tabular}{|c|c|c|c|c|}
\hline \multicolumn{5}{|c|}{$\begin{array}{l}\text { Table } 4 \\
\text { Material Properties for the RCC-to-Limestone Interface Elements } \\
\text { of the SOILSTRUCT-ALPHA Finite Element Model of McAlpine } \\
\text { Lock (47.88 Pa = } 1 \mathrm{psf}, 1 \mathrm{MPa} / \mathrm{m}=3.684 \mathrm{psi} / \mathrm{in} ., 1 \mathrm{MPa} / \mathrm{m}= \\
6,365.9 \mathrm{psf} / \mathrm{ft})\end{array}$} \\
\hline \multirow[b]{2}{*}{ Interface Region } & \multicolumn{2}{|c|}{ Strength Parameters } & \multicolumn{2}{|c|}{ Stiffness Parameters } \\
\hline & $c^{\prime}, p s f$ & $\phi^{\prime}$, deg & $k_{\mathbf{n}}, p s i / i n$. & $k_{n}, p s f / f t$ \\
\hline RCC-to-Limestone & 2300 & 41 & 10,000 & $1.0 \times 10^{8}$ \\
\hline \multicolumn{5}{|c|}{ Equations for Interface Model } \\
\hline \multicolumn{5}{|c|}{ The normal stress at the center of the interface element is given by } \\
\hline \multicolumn{5}{|c|}{$\sigma_{n}=k_{n} \Delta_{n}$} \\
\hline \multicolumn{5}{|c|}{$\begin{array}{l}\text { where } \Delta_{n} \text { is the average relative displacement normal to the interface element. The shear stress at } \\
\text { the center of the interface element is given by }\end{array}$} \\
\hline \multicolumn{5}{|l|}{$T_{s}=k_{s} \Delta_{s}$} \\
\hline
\end{tabular}

effective normal stress below the heel of the new RCC lock ( $x=47 \mathrm{ft}$ ) is equal to $1,626 \mathrm{psf}\left(7,939 \mathrm{~kg} / \mathrm{m}^{2}\right)$. Flooding of the lock chamber to el 383 and partial submergence of the backfill to el 395 (load case 38 ) reduce the effective normal stresses and increase the shear stresses along the base, as shown in Figures 7 and 8. The effective normal stress below the heel of the new RCC lock is reduced to $0 \mathrm{psf}\left(\mathrm{kg} / \mathrm{m}^{2}\right)$; however, full base area contact is maintained.

\section{Results after backfilling to el $\mathbf{4 2 5}$}

Figures 9 and 10 show the variation of horizontal effective stress $\sigma_{x}^{\prime}$ and shear stress $\tau_{x y}$ with elevation along a vertical plane extending through the backfill from the heel of the new RCC lock wall $(x=47 \mathrm{ft}(14.33 \mathrm{~m})$ ) after backfilling to el 425 (load case 24 in Table 1). This section is designated as section A-A (see Figure 11) throughout this report. As anticipated, these figures show the resulting effective horizontal and shear stress distributions to increase with depth below the surface of the backfill.

The resultant horizontal effective force of the Figure 9 distribution of $\sigma_{x}^{\prime}, F_{x}$, is equal to $83,367 \mathrm{lb}$ per $\mathrm{ft}$ run of wall $(1,216.7 \mathrm{kN}$ per $\mathrm{m})$ and acts at el 390.28 $\left(=0.37 \mathrm{H}_{\text {backfill }}\right)$ along section $\mathrm{A}-\mathrm{A}$. The horizontal earth pressure coefficient $\mathrm{K}_{\mathrm{h}}$ is computed along section A-A using the relationship

$$
K_{h}=\frac{F_{x}^{\prime}}{\text { Effective Overburden }}
$$




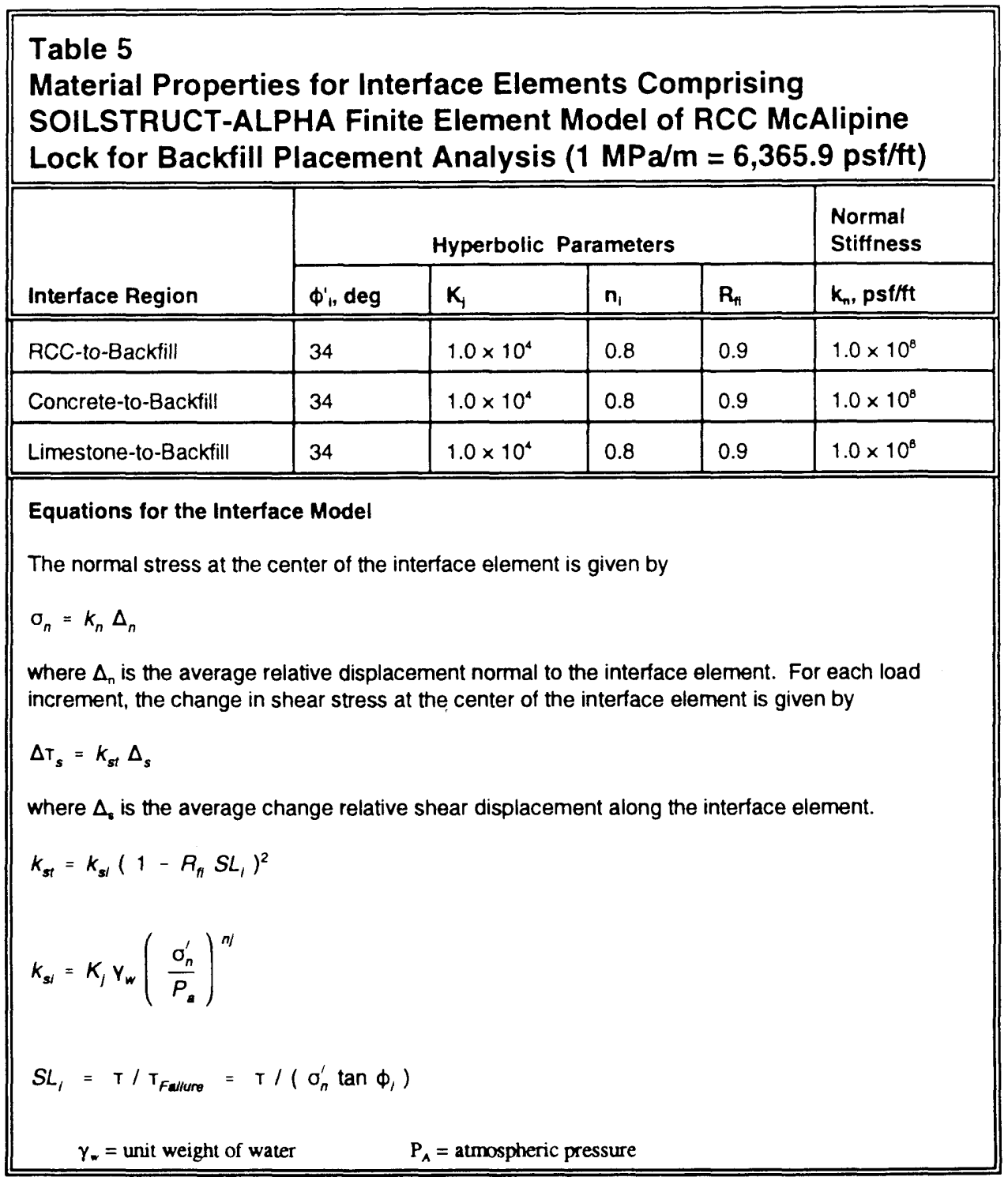

where the Effective Overburden is defined as

$$
\text { Effective Overburden }=\int_{E l 370}^{E l 425} \sigma_{\text {overburden }}^{\prime} d y
$$

In the case of a $55-\mathrm{ft}-(16.76-\mathrm{m})$ high column of moist backfill with $\gamma_{\text {moist }}$ equal to $126 \mathrm{pcf}\left(2,018.3 \mathrm{~kg} / \mathrm{m}^{3}\right)$, Equation 2 for the Effective Overburden becomes

Effective Overburden $=\frac{1}{2} \gamma_{\text {moist }}(H)^{2}$ 


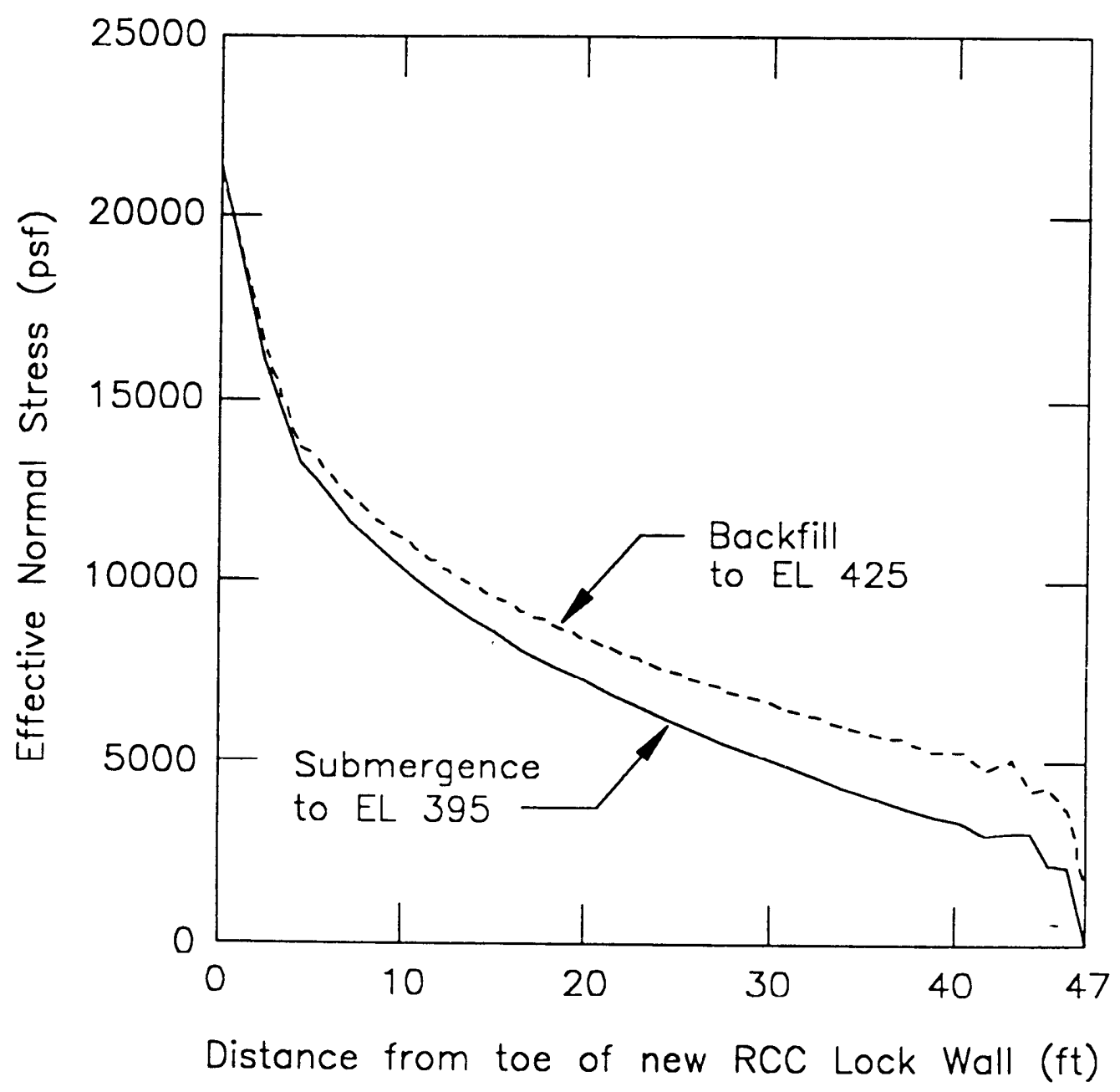

Figure 7. Effective normal stress distributions along the base of new RCC lock wall $(0.305 \mathrm{~m}=1 \mathrm{ft}$, $47.88 \mathrm{~Pa}=1 \mathrm{psf})$

and is equal to $190,575 \mathrm{lb}$ per $\mathrm{ft}$ run of wall $(2,781.2 \mathrm{kN}$ per $\mathrm{m})$. The value for $\mathrm{K}_{\mathrm{h}}$ after backfilling to el 425 is equal to 0.437 by Equation 1 .

Calculation of the resultant horizontal effective force $F_{x}$ of the resulting distributions of $\sigma_{x}^{\prime}$ with elevation in the backfill is made after backfilling to el 425 for two other vertical sections. Figure 11 shows the locations of the three sections used in the summary of the results. The two additional sections are designated as section B-B at $x=74.5 \mathrm{ft}(22.7 \mathrm{~m})$, and section $C-C$ at $x=100.9 \mathrm{ft}(30.75 \mathrm{~m})$.

Table 6 summarizes the results of calculations made to determine the 


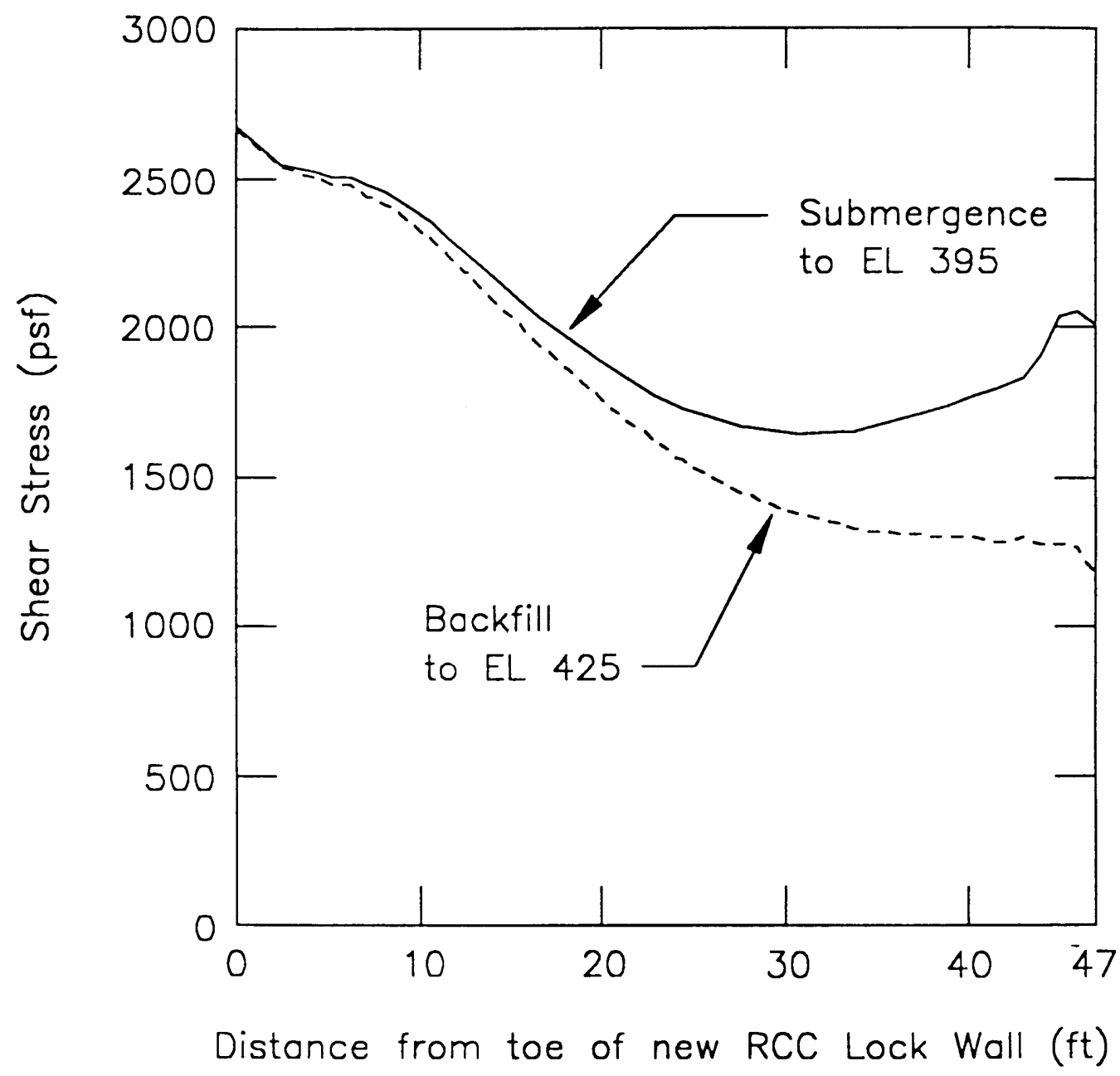

Figure 8. Shear stress distributions along the base of new RCC lock wall $(0.305 \mathrm{~m}=1 \mathrm{ft}, 47.88 \mathrm{~Pa}=$ 1 psf)

resultant horizontal effective force $F_{x}$ and horizontal earth pressure coefficient $K_{h}$ at sections A-A, B-B, and C-C. The table shows the resultant horizontal effective force $F_{x}$ for these two distributions of $\sigma_{x}^{\prime}$ (not shown) result in values of $F_{x}$ equal to $83,520 \mathrm{lb}$ per $\mathrm{ft}$ run of wall $(1,218.9 \mathrm{kN}$ per m) (section $\mathrm{B}-\mathrm{B})$ and $71,198 \mathrm{lb}$ per $\mathrm{ft}$ run of wall $(1,039.1 \mathrm{kN}$ per $\mathrm{m})$ (section $\mathrm{C}-\mathrm{C})$. Figure 11 also shows the variation in horizontal earth pressure coefficient $\mathrm{K}_{\mathrm{b}}$, within distance from the back of the new RCC lock wall for the three sections. Figure 11 shows the values for $K_{h}$ equals 0.437 adjacent to the new RCC lock wall (section A-A, 0.438 at section B-B, and 0.374 adjacent to the existing lock wall (section C-C). 


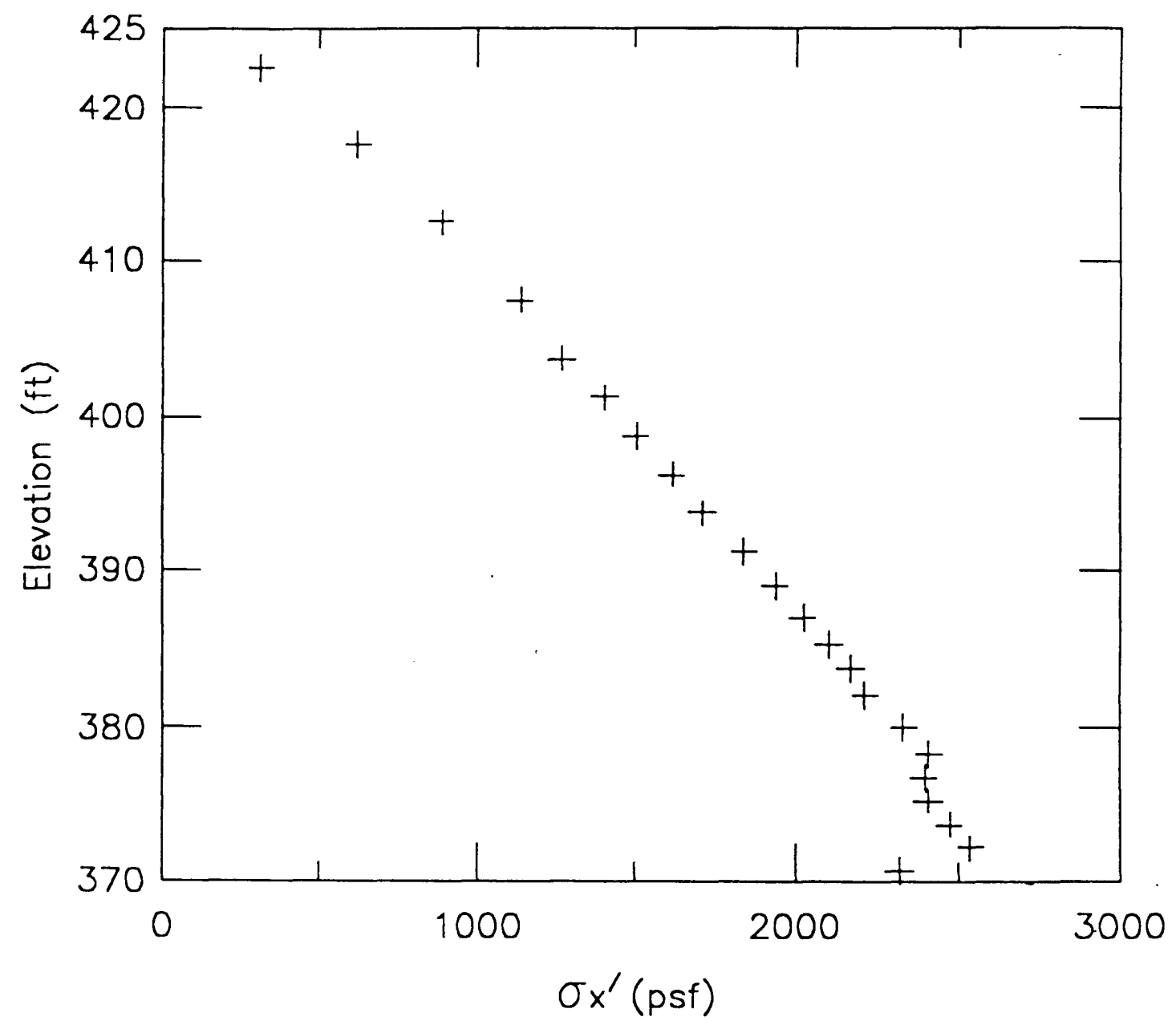

Figure 9. Horizontal effective stress distributions along section A-A after backfilling to el $425(0.305 \mathrm{~m}=$ $1 \mathrm{ft}, 47.88 \mathrm{~Pa}=1 \mathrm{psf})$

Note that the values for $K_{\mathrm{t}}$ at sections A-A and B-B are just slightly less than 0.44 , the value for $\mathrm{K}_{\mathrm{o}}$ from the 1-D soil column settlement analysis reported in Appendix A. Recall that the conditions corresponding to a $\mathrm{K}_{\mathrm{o}}$ stress state within the soil exist in a region of constrained, uniform settlement. The value of $\mathrm{K}_{\mathrm{t}}$ at section $\mathrm{C}-\mathrm{C}$ is 18 percent less than the $K_{o}$ value because of the influence of the large vertical shear force acting along this plane (to be discussed subsequently) resulting from the presence of the existing concrete lock wall at $x=102 \mathrm{ft}(31.09 \mathrm{~m})$.

The resultant vertical shear force of the Figure 10 distribution of $\tau_{x y}, F_{v}$, is equal to $11,416 \mathrm{lb}$ per $\mathrm{ft}$ run of wall $(166.6 \mathrm{kN}$ per $\mathrm{m})$ along section A-A. The 


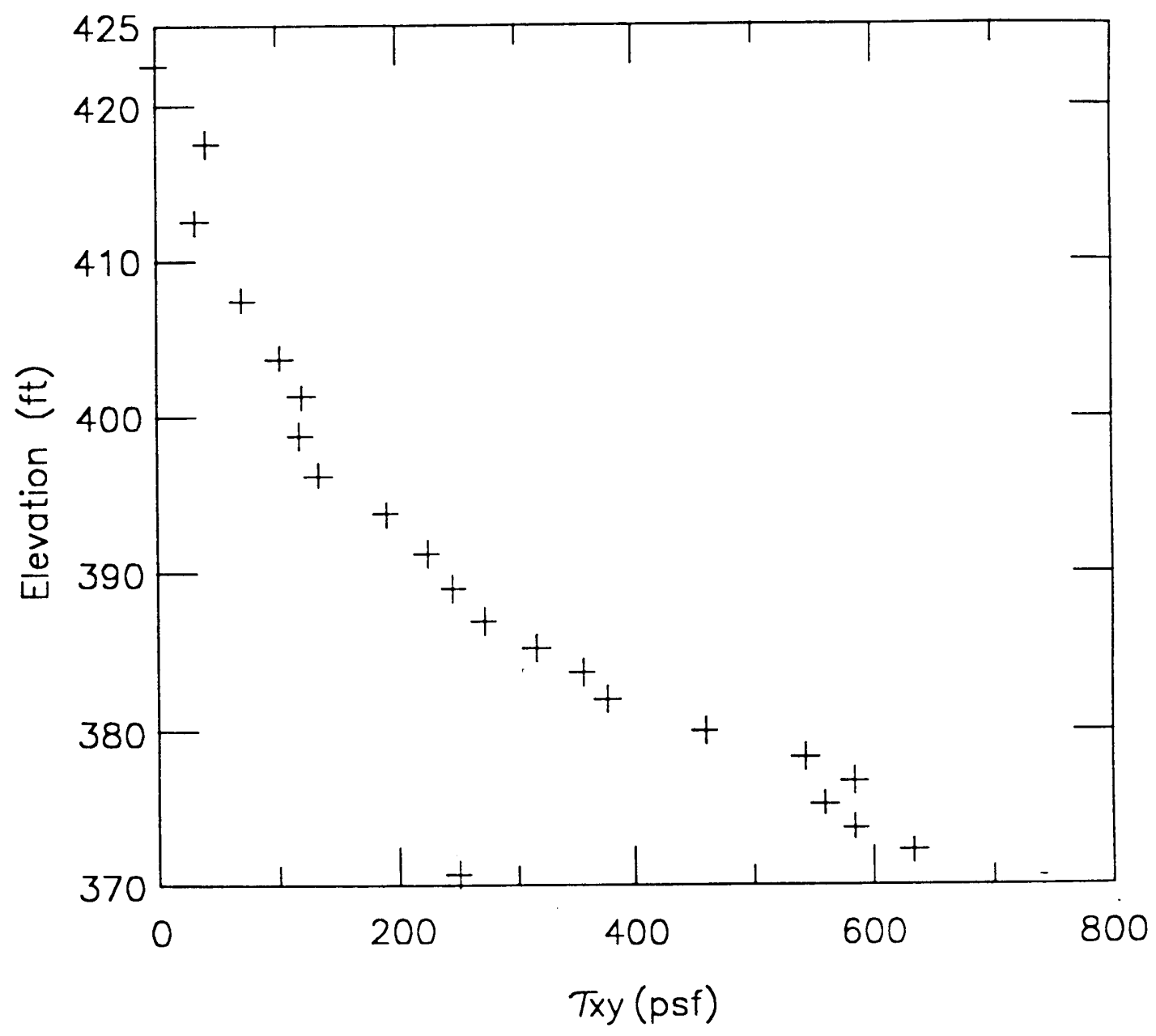

Figure 10. Shear stress distributions along section A-A after backfilling to el $425(0.305 \mathrm{~m}=1 \mathrm{ft}$, $47.88 \mathrm{~Pa}=\mathrm{psf}$ )

vertical earth pressure coefficient $K_{v}$ is computed along section A-A using the relationship

$$
K_{v}=\frac{F_{v}}{\text { Effective Overburden }}
$$

where the Effective Overburden is equal to $190,575 \mathrm{lb}$ per $\mathrm{ft}$ run of wall $(2,781.2 \mathrm{kN}$ per $\mathrm{m})$ by Equation 3. The value for $\mathrm{K}_{\mathrm{v}}$ after backfilling to el 425 is equal to 0.06 by Equation 4 . 

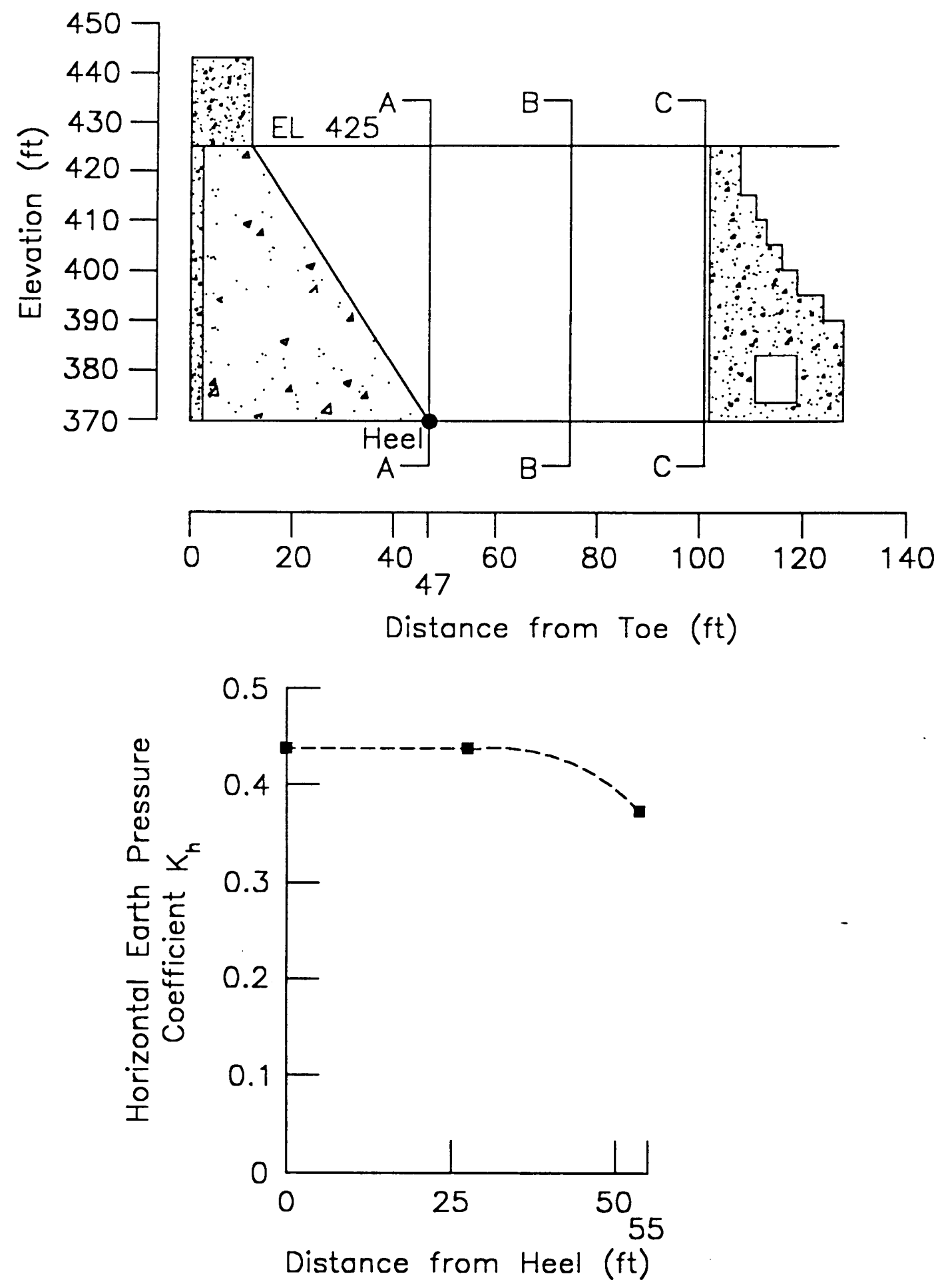

Figure 11. Variation of horizontal earth pressure coefficient, $K_{n}$ with distance from heel of new RCC lock wall after backfilling to el $425(0.305 \mathrm{~m}=1 \mathrm{ft})$ 


\begin{tabular}{|c|c|c|c|c|c|}
\hline \multicolumn{6}{|c|}{$\begin{array}{l}\text { Table } 6 \\
\text { Summary of SOILSTRUCT-ALPHA Results After Backfilling New } \\
\text { RCC McAlpine Lock to el } 425 \text { ( } 14.594 \mathrm{~N} \text { per } m=1 \text { lb per } \mathrm{ft} \text { run of } \\
\text { wall) }\end{array}$} \\
\hline Section & $\begin{array}{l}\text { Effective Overburden, } \\
\text { Ib per } \mathrm{t} \text { run of wall }\end{array}$ & $\begin{array}{l}F_{x}, \text { lb per } f t \\
\text { run of wall }\end{array}$ & $\begin{array}{l}F_{v}, \text { lb per } \mathrm{ft} \\
\text { run of wall }\end{array}$ & $K_{n}$ & $\mathrm{~K}_{\mathrm{v}}$ \\
\hline$A-A$ & 190,575 & 83,367 & 11,416 & 0.437 & 0.060 \\
\hline B-B & 190,575 & 83,520 & $-4,990$ & 0.438 & -0.026 \\
\hline $\mathrm{C}-\mathrm{C}$ & 190,575 & 71,198 & $-34,869$ & 0.374 & -0.183 \\
\hline
\end{tabular}

Calculation of the resultant vertical shear force $F_{v}$ from the resulting distributions of $\tau_{x y}$ with elevation is made after backfilling to el 425 for sections B-B and C-C. Table 6 summarizes the results of calculations made to determine the resultant vertical shear force $F_{v}$ and vertical earth pressure coefficient $K_{v}$ at sections A-A, B-B, and C-C. The table shows that the resultant vertical shear force, $F_{v}$, for these two distributions of $\tau_{x y}$ (not shown) result in values of $F_{v}$ equal to $4,990 \mathrm{lb}$ per ft run of wall $(72.8 \mathrm{kN}$ per m) (section B-B) and $34,869 \mathrm{lb}$ per $\mathrm{ft}$ run of wall ( $508.9 \mathrm{kN}$ per $\mathrm{m}$ ) (section $\mathrm{C}-\mathrm{C}$ ). Figure 12 shows the variation in vertical earth pressure coefficient $\mathrm{K}_{\mathrm{v}}$, within distance from the back of the new $\mathrm{RCC}$ lock wall for the three sections. Figure 12 shows the values for $\mathrm{K}_{\mathrm{v}}$ equal 0.06 adjacent to the new RCC lock wall (section A-A), 0.026 at section B-B, and 0.183 adjacent to the existing lock wall (section $C-C$ ). The values for $\mathrm{K}_{\mathrm{v}}$ for sections $\mathrm{B}-\mathrm{B}$ and $\mathrm{C}-\mathrm{C}$ are plotted as negative values to note that the corresponding vertical shear forces at these sections act counter to the direction of $F_{v}$ along section A-A, as shown in the three diagrams in Figure 12. Note that had there been no differential settlement across a vertical section in the backfill, $F_{v}$ and $K_{v}$ would be equal to 0 . (This is the case for the settlement of the Appendix A 1-D soil column due to self-weight.) $F_{v}$ and $K_{v}$ are nonzero at the three sections because of the close proximity of the two shear faces fumished by the new RCC lock and the existing lock walls.

Table 7 summarizes the resultant forces and their points of application on the free body of the new RCC lock wall shown in Figure 13 after backfilling to el 425. These resultant forces and their points of application are computed by SOILSTRUCT-ALPHA using the distributions of effective normal and shear stresses computed within the interface elements located along the back of the new RCC lock wall and along the base of the lock wall for load case 24 . Twenty-two interface elements delineate the back of the RCC lock wall, and thirty interface elements delineate the base of the lock wall. The Table 7 values of forces and their points of application are consistent with the actual distribution of stresses along the two planes defined by the two groups of interface elements because of the analytical formulation used to define the interface elements in SOILSTRUCTALPHA. The Table 7 results show that the amount of shear (or "downdrag") along the back of the new RCC lock wall is significant and corresponding to a mobilized angle of interface friction $\delta_{\text {mob }}$ equal to $25.28 \mathrm{deg}$. 

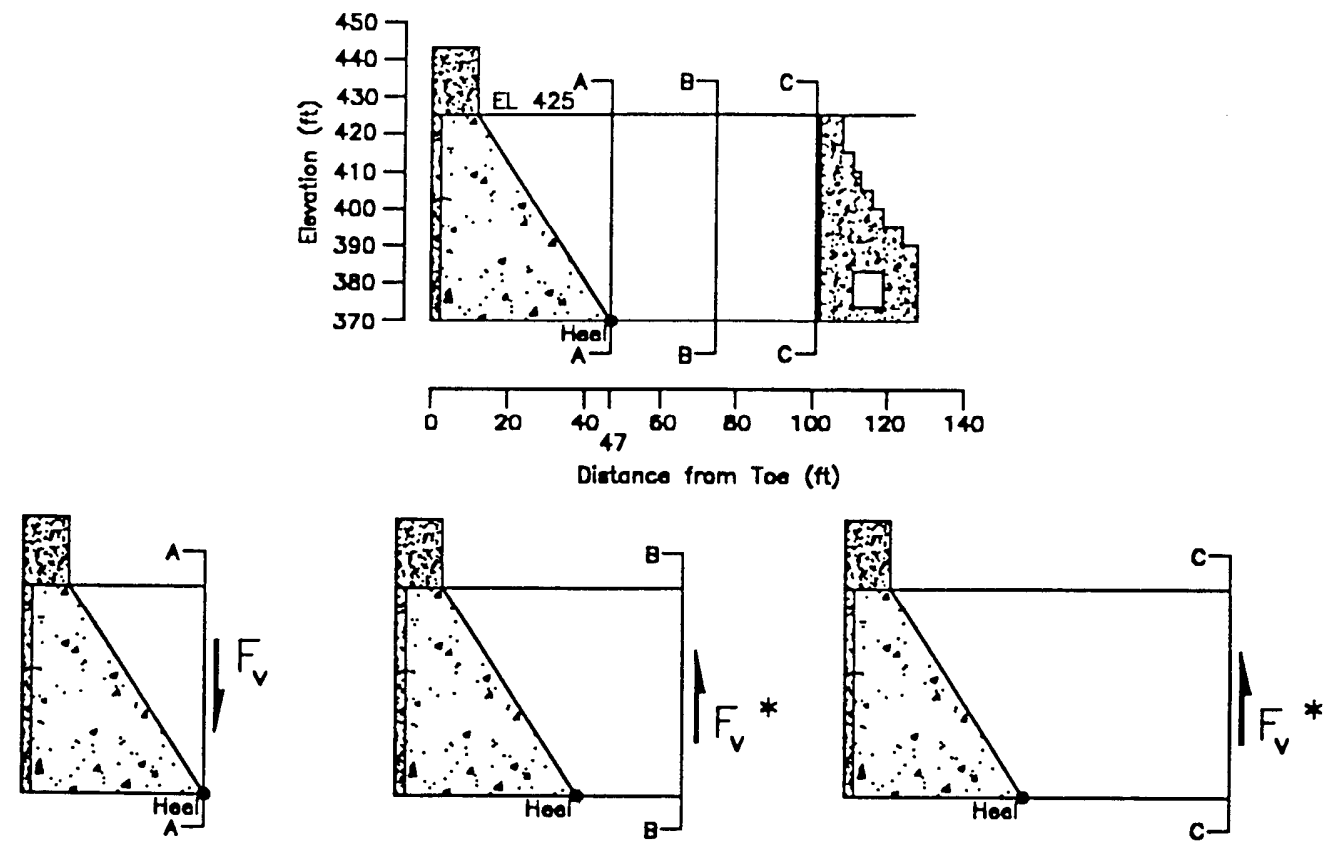

$F_{v}=K_{v} \cdot$ (Effective Overburden)

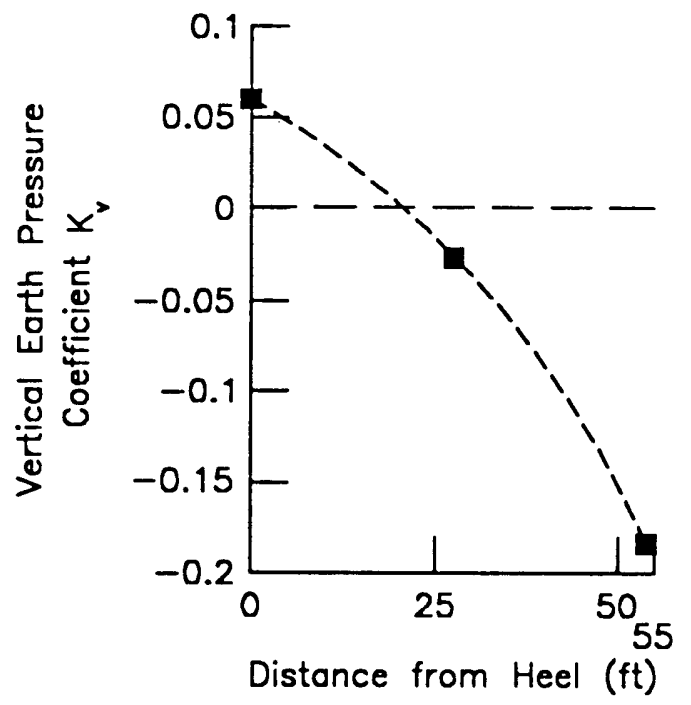

* Negative values of $K_{v}$ reflect $F_{v}$ directed upward on sections $B-B$ and $C-C$

Figure 12. Variation of vertical earth pressure coefficient, $K_{w}$ with distance from heel of new RCC lock wall after backfilling to el $425(0.305 \mathrm{~m}=1 \mathrm{ft})$ 


\section{Table 7}

Summary of SOILSTRUCT-ALPHA Results After Backfilling New RCC McAlpine Lock to

El $425(14.594 \mathrm{~N}$ per $\mathrm{m}=1 \mathrm{lb}$ per $\mathrm{ft}$ run of wall, $0.305 \mathrm{~m}=1 \mathrm{ft})$

\begin{tabular}{|c|c|c|c|c|c|c|c|c|c|}
\hline $\begin{array}{l}\text { Load } \\
\text { Case }\end{array}$ & $\begin{array}{l}F_{\text {. I }} \text { ib per } \mathrm{H} \\
\text { run of wall }\end{array}$ & $\begin{array}{l}F_{n} \text {, lb per ft run } \\
\text { of wall }\end{array}$ & $I_{F n} / L$ & $I_{E_{n}} L$ & $\begin{array}{l}\delta_{\text {mos, }} \\
\text { deg }\end{array}$ & $\begin{array}{l}T, \text { lb per } \mathrm{ft} \\
\text { run of wall }\end{array}$ & $\begin{array}{l}\mathrm{N} \text {, Ib per } \mathrm{Ht} \\
\text { run of wall }\end{array}$ & $x_{N} / f t$ & $\underline{x}_{N}, \mathrm{~B}$ \\
\hline 24 & 66.435 & 140,661 & 21.96 & 0.34 & 25.28 & 83,003 & 405,573 & 17.98 & 0.38 \\
\hline
\end{tabular}

Note:

where $B=47 \mathrm{ft}, L=65.19 \mathrm{ft}$, and $\tan \left(\delta_{m \infty}\right)=\frac{F_{s}}{F_{n}^{\prime}}$

\section{Results after partial submergence to el 395}

Figures 14 and 15 show the variation of horizontal effective stress $\sigma_{x}^{\prime}$ and shear stress $\tau_{x y}$ with elevation along section A-A after backfilling to el 425 and after partial submergence of the backfill to el 395 (load cases 24 and 38, respectively). As anticipated, these figures show that the resulting effective horizontal and shear stress distributions increase with depth below the surface of the backfill. Figure 14 shows that the magnitude of the values of $\sigma_{x}^{\prime}$ below el 395 decreases with the partial submergence of the site. Figure 15 shows that the magnitude of the values of $\tau_{x y}$ decreases with the partial submergence of the site. During postconstruction, after partial submergence of the backfill to el 395, the buoyancy forces act upward, thereby unloading the backfill. This also results in a reversal in shear stress increment.

The resultant horizontal effective force of the Figure 14 distribution of $\sigma_{x}^{\prime}, F_{x}$, is equal to $79,102 \mathrm{lb}$ per $\mathrm{ft}$ run of wall $(1,154.4 \mathrm{kN}$ per m) and acts at el 390.99 $\left(=0.38 \mathrm{H}_{\text {backfill }}\right)$ along section $\mathrm{A}-\mathrm{A}$ after partial submergence of the backfill to el 395. The horizontal earth pressure coefficient $K_{\mathrm{t}}$ is computed along section A-A using Equation 1, with the Effective Overburden computed using Equation 2. In the case of partially submerged, $55-\mathrm{ft}-(16.76-\mathrm{m}-)$ high column [with $\gamma_{\text {moist }}$ equal to $126 \mathrm{pcf}\left(2,018.32 \mathrm{~kg} / \mathrm{m}^{3}\right)$ and $\gamma_{\text {seturated }}$ equal to $\left.130 \mathrm{pcf}\left(2,082.39 \mathrm{~kg} / \mathrm{m}^{3}\right)\right]$, Equation 2 for the Effective Overburden becomes

$$
=\left[\frac{1}{2} \gamma_{\text {moist }}\left(D_{1}\right)^{2}+\gamma_{\text {moist }}\left(D_{1} D_{2}\right)+\frac{1}{2} \gamma_{\text {buy }}\left(D_{2}\right)^{2}\right]
$$

where

$D_{1}=$ the thickness of backfill above the hydrostatic water table $=30 \mathrm{ft}(9 \mathrm{~m})$

$D_{2}=$ the thickness of submerged backfill above the base of the wall $=25 \mathrm{ft}$ $(7.6 \mathrm{~m})$ 


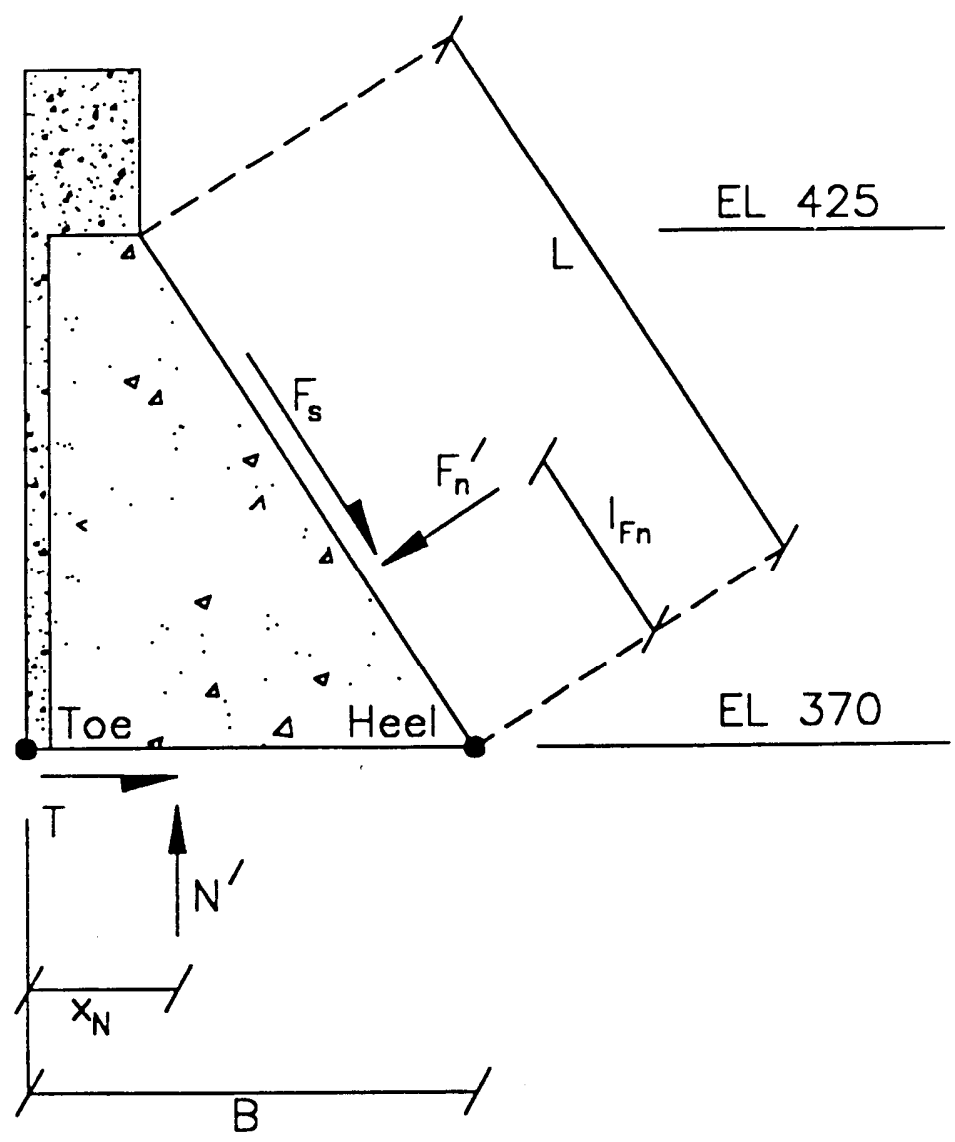

Figure 13. Planes along surfaces of the new RCC lock on which resultant forces are computed after backfill is placed to el $425(0.305 \mathrm{~m}=1 \mathrm{ft})$

$$
\begin{aligned}
& \gamma_{\text {buy }}=\text { buoyant unit weight of submerged backfill, } \gamma_{\text {saturated }}-\gamma_{w} \\
& \gamma_{w}=\text { unit weight of water }=62.4 \mathrm{pcf}\left(999.55 \mathrm{~kg} / \mathrm{m}^{3}\right)
\end{aligned}
$$

and is equal to $172,325 \mathrm{lb}$ per $\mathrm{ft}$ run of wall $\left(2,514.9 \mathrm{kN}\right.$ per m). The value for $\mathrm{K}_{\mathrm{h}}$ after partial submergence of the backfill to el 395 is equal to 0.459 by Equation 1 .

Calculation of the resultant horizontal effective force $F_{x}$ of the resulting distributions of $\sigma_{x}^{\prime}$ with elevation in the backfill is made after partial submergence of the backfill to el 395 for sections B-B and C-C. Table 8 summarizes the results of calculations made to determine the resultant horizontal effective force $F_{x}$ and horizontal earth pressure coefficient $K_{h}$ at sections A-A, B-B, and 


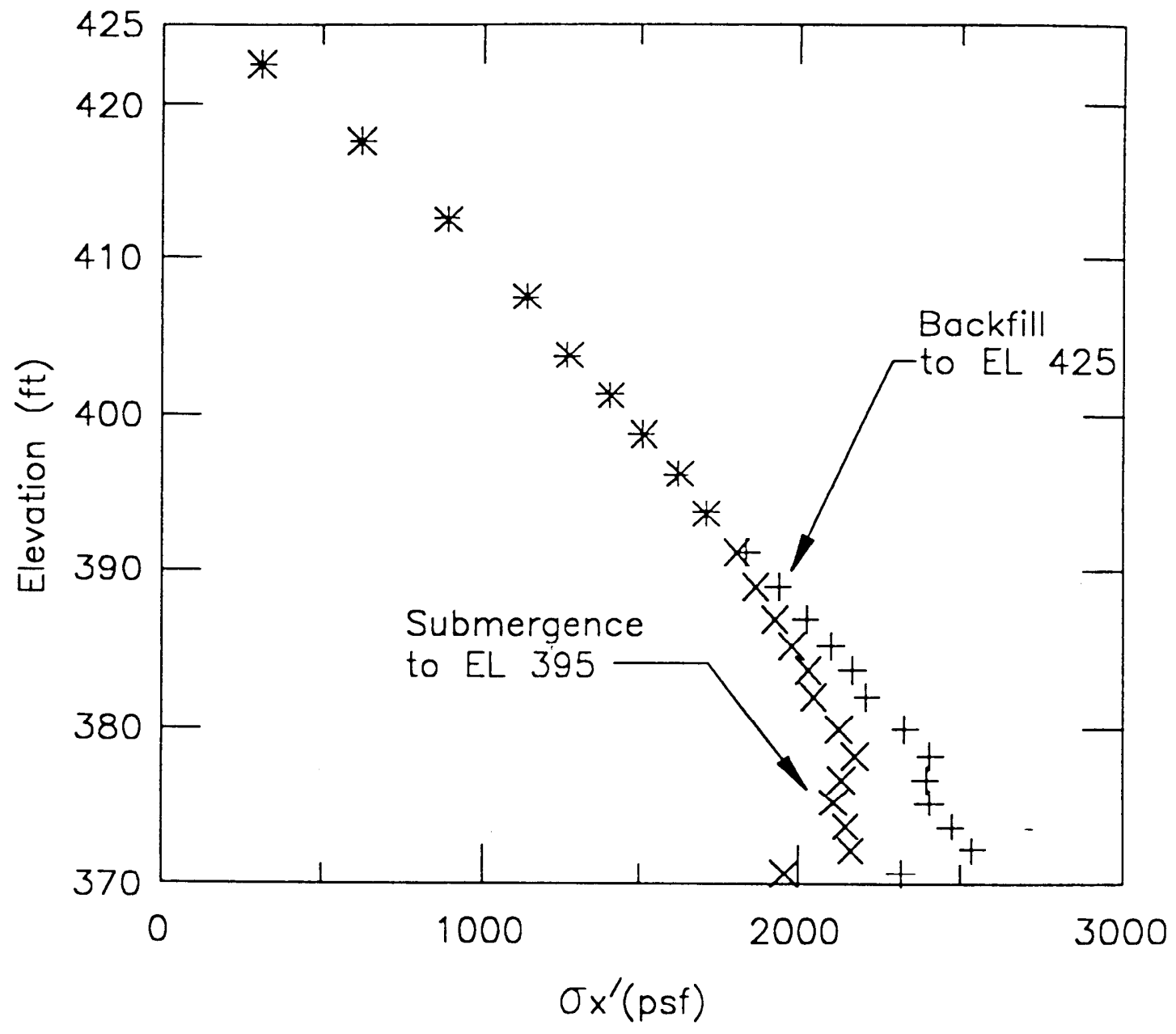

Figure 14. Horizontal effective stress distributions along section $\mathrm{A}-\mathrm{A}(0.305 \mathrm{~m}=1 \mathrm{ft}, 47.88 \mathrm{~Pa}=1 \mathrm{psf})$

C-C. The table shows the resultant horizontal effective force $F_{x}$ for these two distributions of $\sigma_{\mathrm{x}}^{\prime}$ (not shown) result in values of $F_{\mathrm{x}}$ equal to $79,022 \mathrm{lb}$ per $\mathrm{ft}$ run of wall $(1,153.2 \mathrm{kN}$ per m) (section B-B) and $68,475 \mathrm{lb}$ per $\mathrm{ft}$ run of wall ( $999.3 \mathrm{kN}$ per $\mathrm{m}$ ) (section $\mathrm{C}-\mathrm{C}$ ). Figure 16 shows the variation in horizontal earth pressure coefficient $K_{h}$, with distance from the back of the new RCC lock wall for the three sections. Figure 16 shows the values for $K_{t}$ equals 0.459 adjacent to the new RCC lock wall (section A-A), 0.459 at section B-B, and 0.397 adjacent to the existing lock wall (section C-C). The values for $\mathrm{K}_{\mathrm{h}}$ after partial submergence of the backfill to el 395 (Figure 16) are greater than the values for $\mathrm{K}_{\mathrm{h}}$ after backfilling to el 425 (Figure 11) as a result of the "unloading" of the soil during submergence. 


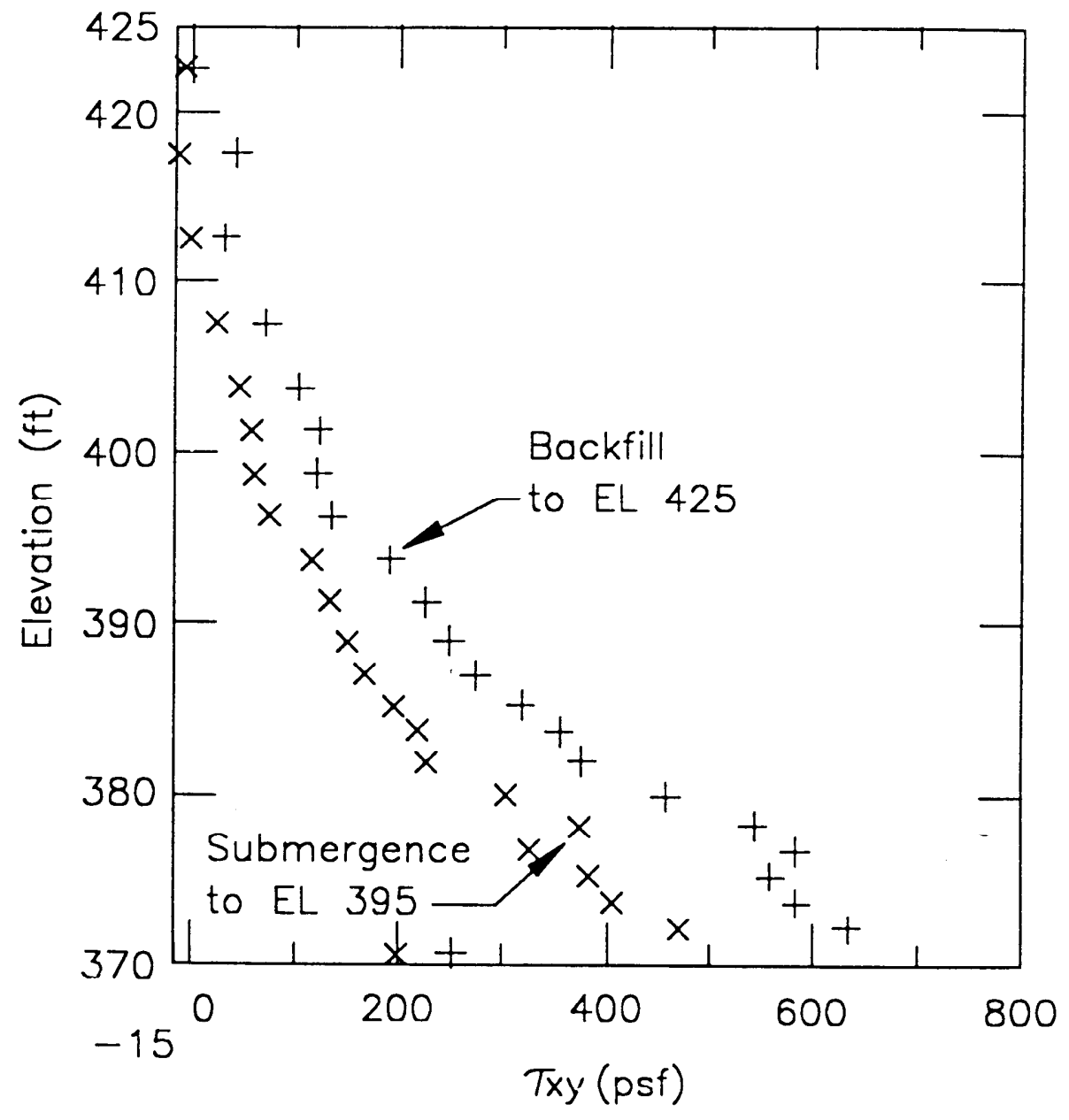

Figure 15. Shear stress distributions along section $A-A(0.305 m=1 \mathrm{ft}, 47.88 \mathrm{~Pa}=1 \mathrm{psf})$

The resultant vertical shear force of the Figure 15 distribution of $\tau_{x y}, F_{v}$, is equal to $6,775 \mathrm{lb}$ per $\mathrm{ft}$ run of wall $(98.9 \mathrm{kN}$ per $\mathrm{m})$ along section $\mathrm{A}-\mathrm{A}$. The vertical earth pressure coefficient $K_{v}$ is computed along section $A-A$ using Equation 4 with the Effective Overburden equal to $172,325 \mathrm{lb}$ per $\mathrm{ft}$ run of wall $(2,514.9 \mathrm{kN}$ per m) by Equation 5. The value for $\mathrm{K}_{\mathrm{v}}$ after partial submergence of the backfill to el 395 is equal to 0.039 by Equation 4 .

Calculation of the resultant vertical shear force $F_{v}$ of the resulting distribu-tions of $\tau_{x y}$ with elevation in the backfill is made after partial submergence of the backfill to el 395 for sections $B-B(x=74.5 \mathrm{ft}(22.7 \mathrm{~m}))$ and section $C-C(x=$ 


\section{Table 8}

Summary of SOILSTRUCT-ALPHA Results After Backfilling New RCC McAlpine Lock to El 425 and After Submergence to El 395 (14.594 $\mathrm{N}$ per $\mathrm{m}=1 \mathrm{lb}$ per $\mathrm{ft}$ run of wall)

\begin{tabular}{|c|c|c|c|c|c|}
\hline Section & $\begin{array}{l}\text { Effective Overburden, Ib } \\
\text { per } \mathrm{ft} \text { run of wall }\end{array}$ & $\begin{array}{l}F_{x}{ }^{\prime}, l b \text { per } f t \text { run of } \\
\text { wall }\end{array}$ & $\begin{array}{l}F_{v}, \text { Ib per } f t \\
\text { run of wall }\end{array}$ & $K_{h}$ & $\mathbf{K}_{\mathbf{r}}$ \\
\hline$A-A$ & 172,325 & 79,102 & 6,775 & 0.459 & 0.039 \\
\hline B-B & 172,325 & 79,022 & $-4,241$ & 0.459 & -0.025 \\
\hline$C-C$ & 172,325 & 68,475 & $-25,389$ & 0.397 & -0.147 \\
\hline
\end{tabular}

$100.9 \mathrm{ft}(30.75 \mathrm{~m}))$, with the results summarized in Table 8 . The table shows the resultant vertical shear force $F_{v}$ for these two distributions of $\tau_{x y}$ (not shown) result in values of $F_{v}$ equal to 4,241 (section B-B) and 25,389 (section C-C). Figure 17 shows the variation in vertical earth pressure coefficient $\mathrm{K}_{v}$, within distance from the back of the new RCC lock wall for the three sections. Figure 17 shows the values for $K_{v}$ equal 0.039 adjacent to the new RCC lock wall (section A-A), 0.025 at section B-B, and 0.147 adjacent to the existing lock wall (section $\mathrm{C}-\mathrm{C}$ ). The values for $\mathrm{K}_{\mathrm{v}}$ after partial submergence of the backfill to el 395 (Figure 17) are less than the values for $K_{v}$ after backfilling to el 425 (Figure 12). This behavior is a result of the buoyancy forces acting upward, thereby unloading the backfill and reversing the direction of the applied shear stresses (as compared to their direction during backfilling) along the faces of the new RCC and existing lock walls.

Table 9 summarizes the resultant forces and their points of application on the free body of the new RCC lock wall through which imaginary section(s) (shown in Figure 18) are made. These resultant forces and their points of application are computed by SOILSTRUCT-ALPHA after backfilling to el 425 (load case 24 in Table 1) and after partial submergence of the backfill to el 395 (load case 38). The Table 9 results show that the shear force $F_{s}$ along the back of the new RCC lock wall is reduced by 16.6 percent with submergence of the backfill to el 395 as compared to the results in Table 7 (load case 24). The mobilized angle of interface friction $\delta_{\text {mob }}$ is reduced from 25.28 to $23.33 \mathrm{deg}$ with partial submergence of the backfill.

\section{Summary}

This report summarizes the results of a complete soil-structure interaction analysis of the new RCC McAlpine Lock using SOILSTRUCT-ALPHA. The principal results are as follows:

a. A complete soil-structure interaction analysis of the new RCC McAlpine Lock results in nonlinear effective normal and shear stress distributions 

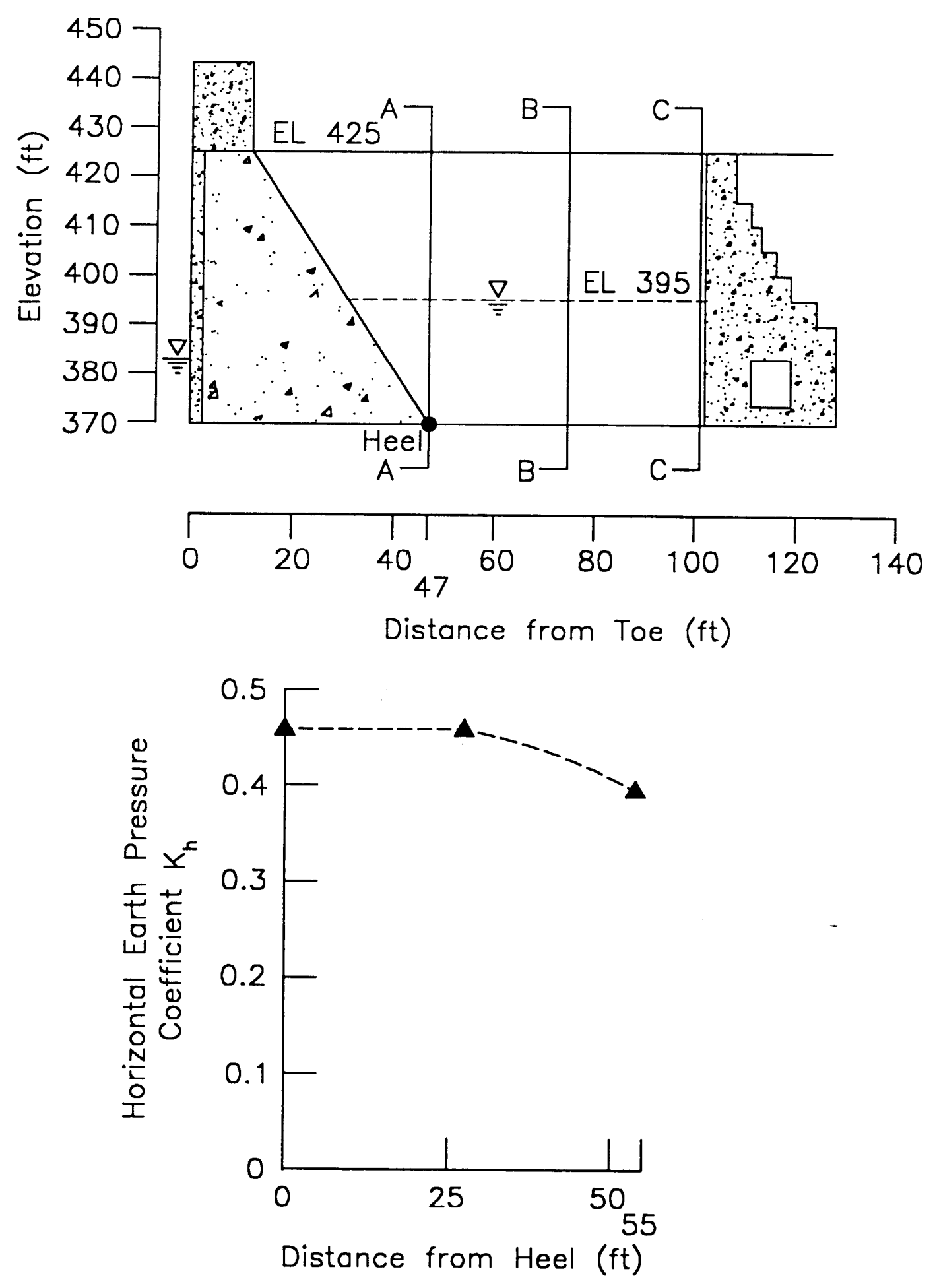

Figure 16. Variation of horizontal earth pressure coefficient, $K_{r}$ with distance from heel of new RCC lock wall after submergence to el $395(0.305 \mathrm{~m}=1 \mathrm{ft})$ 

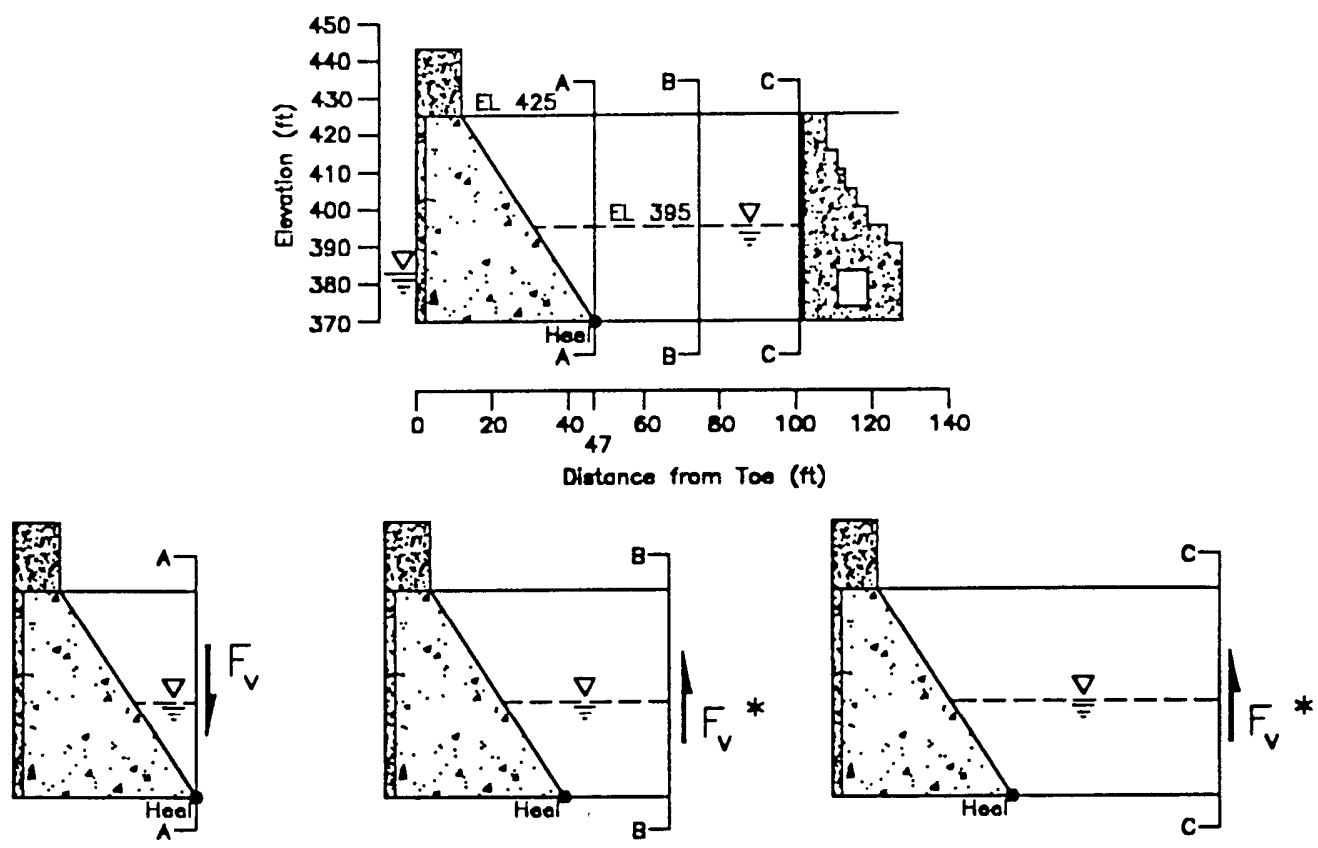

$F_{v}=K_{v} \cdot$ (Effective Overburden)

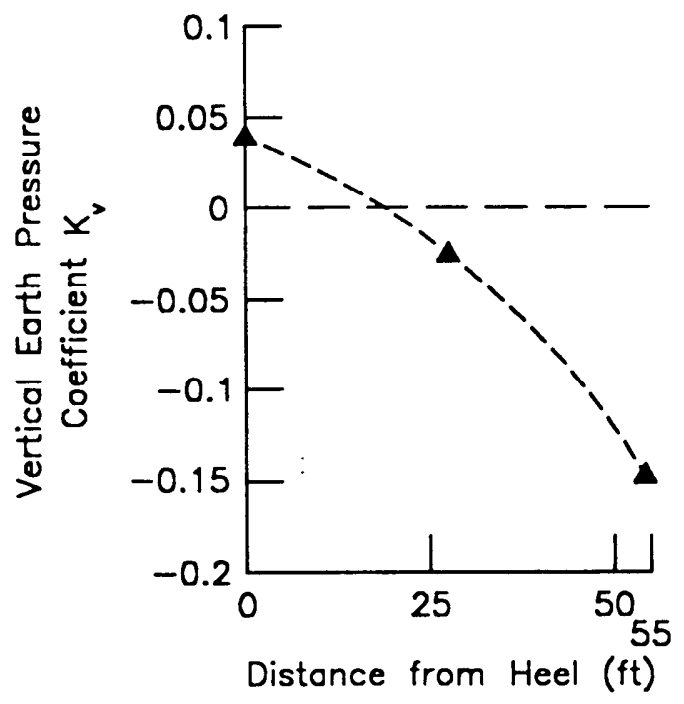

* Negative values of $K_{v}$ reflect $F_{v}$ directed upward on sections $B-B$ and $C-C$

Figure 17. Variation of vertical earth pressure coefficient, $\mathrm{K}_{w}$ with distance from heel of new RCC lock wall after submergence to el $395(0.305 \mathrm{~m}=1 \mathrm{ft})$ 


\section{Table 9}

Summary of SOILSTRUCT-ALPHA Results After Backfilling New RCC McAlpine Lock to El 425 and After Submergence to El 395 (14.594 $\mathrm{N}$ per $\mathrm{m}=1 \mathrm{lb}$ per $\mathrm{ft}$ run of wall, $0.305 \mathrm{~m}=1 \mathrm{ft}$ )

\begin{tabular}{|c|c|c|c|c|c|c|c|c|c|}
\hline \multicolumn{10}{|c|}{ For Load Cases 24 and 38} \\
\hline $\begin{array}{l}\text { Load } \\
\text { Case }\end{array}$ & $\begin{array}{l}\text { F., lb per } \\
\text { ft run of } \\
\text { wall }\end{array}$ & $\begin{array}{l}F_{n}, \text { lb per } \\
\text { ft run of } \\
\text { wall }\end{array}$ & $I_{F n} / f t$ & $I_{\mathrm{Fn}} \Omega$ & $\begin{array}{l}\delta_{\text {mobs }} \\
\text { deg }\end{array}$ & $\begin{array}{l}T \text {, lb per } \\
\text { ft run of } \\
\text { wall }\end{array}$ & $\begin{array}{l}N^{\prime} \text {, ib per } \\
\text { tt run of } \\
\text { wall }\end{array}$ & $x_{N}, t t$ & $x_{N} / B$ \\
\hline 24 & 66,435 & 140,661 & 21.96 & 0.34 & 25.28 & 83,003 & 405,573 & 17.98 & 0.38 \\
\hline 38 & 55,404 & 128,436 & 23.32 & 0.36 & 23.33 & 93,820 & 347,902 & 16.18 & 0.34 \\
\hline \multicolumn{10}{|c|}{ For Load Case 38} \\
\hline $\begin{array}{l}\text { Load } \\
\text { Case }\end{array}$ & $\begin{array}{l}U_{\text {bero }} \text { it } \\
\text { per } f t \\
\text { run of } \\
\text { wall }\end{array}$ & $x_{1000,}, f t$ & $\frac{x_{100000}}{B}$ & $\begin{array}{l}U_{\text {trom, }} \text { ib } \\
\text { per ft run } \\
\text { of wall }\end{array}$ & $h_{\text {Utront }}, f t$ & $\begin{array}{l}U_{\text {beck }} \text { ib } \\
\text { per } f t \\
\text { run of } \\
\text { wall }\end{array}$ & $I_{\text {loeck }}, \mathrm{ft}$ & & \\
\hline 38 & 66,435 & 25.97 & 0.55 & $5,272.8$ & 4.33 & 23,113 & 9.88 & & \\
\hline where & $47 \mathrm{ft}, \mathrm{L}=6$ & $9 \mathrm{ft}$, and & & $\frac{F_{s}}{F_{n}^{\prime}}$ & & & & & \\
\hline
\end{tabular}

along the base of the lock at the end of backfilling to el 425 , and after flooding the lock to el 383 and partial submergence of the backfill to el 395 .

$b$. Full base contact is maintained throughout all (38) stages of loading. However, the effective normal stress below the heel of the new RCC lock is reduced to $0(\mathrm{kPa})$ psf after flooding the lock to el 383 and partial submergence of the backfill to el 395 .

c. Among the results computed in a backfill placement analysis is the distribution of horizontal effective stress at three vertical sections in the backfill. At section A-A, the value of the effective horizontal force $F_{x}$ is computed from the distribution of effective horizontal stress $\sigma_{x}^{\prime}$ along a vertical plane extending through the backfill from the heel of the wall. The value for $\mathrm{F}_{\mathrm{x}}$ is also characterized in terms of the value of the horizontal earth pressure coefficient $K_{\mathrm{t}}$. The results of the SSI analysis shows that $F_{\mathrm{x}}$ decreases as a result of the submergence of the backfill and the value of $\mathrm{K}_{\mathrm{h}}$ increases.

d. The value of $K_{h}$ at section C-C is less than the values of $K_{h}$ at sections $\mathrm{A}-\mathrm{A}$ and $\mathrm{B}-\mathrm{B}$ because of the influence of the large vertical shear force 


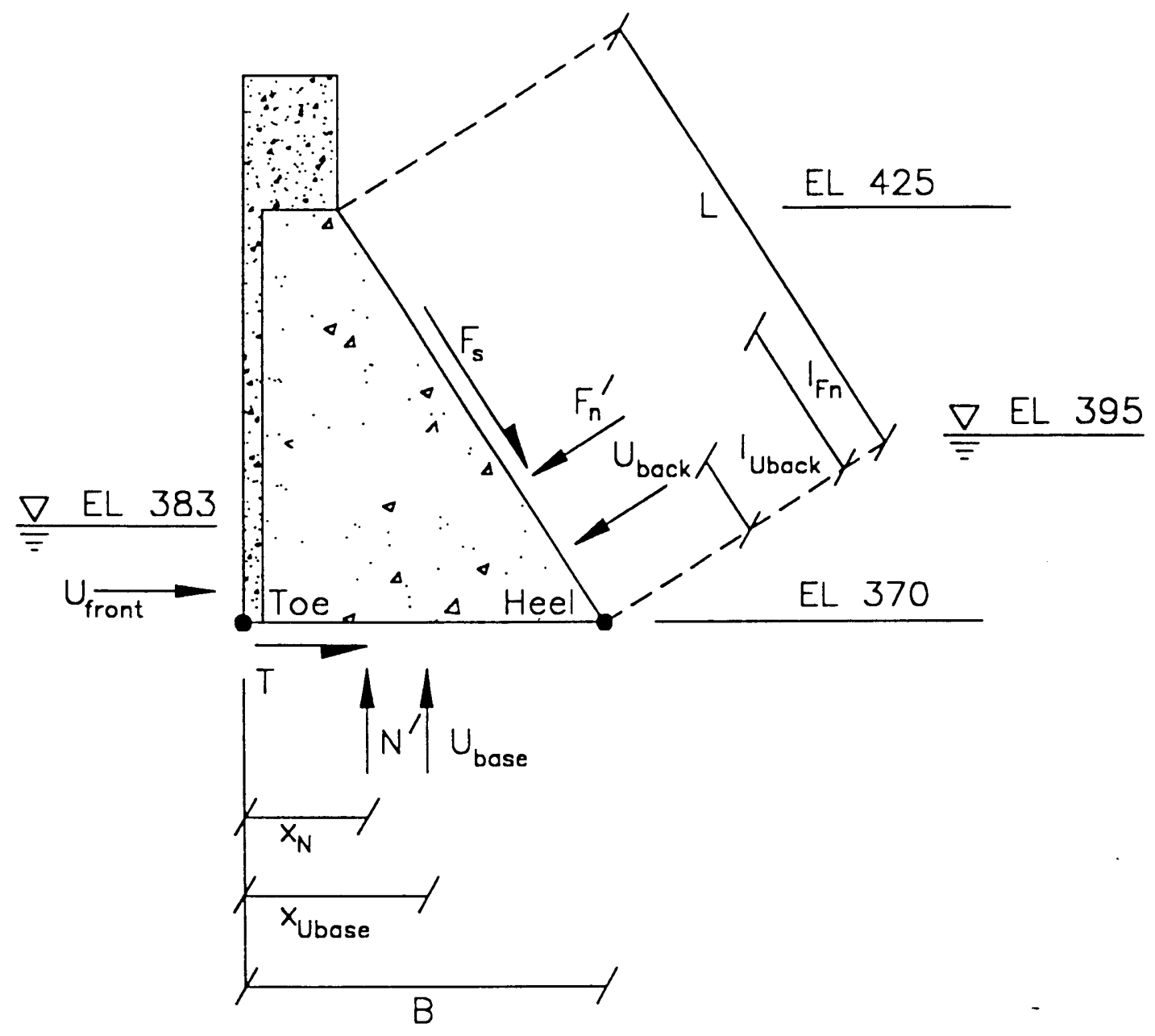

Figure 18. Planes along surfaces of the new RCC lock on which resultant forces are computed submergence to el $395(0.305 \mathrm{~m}=1 \mathrm{ft})$

along this plane, caused by the presence of the existing lock wall. Recall that section $\mathrm{C}-\mathrm{C}$ is immediately adjacent to the existing lock wall.

$e$. The distribution of shear stress at three vertical sections in the backfill is also computed in a backfill placement analysis. At section A-A, the value of the vertical shear force $F_{v}$ is computed from the distribution of shear stress $\tau_{x y}$ along a vertical plane extending through the backfill from the heel of the wall. The value for $F_{v}$ is also characterized in terms of the value of the vertical earth pressure coefficient $\mathrm{K}_{\mathrm{v}}$. The results of the SSI analysis shows that $F_{v}$, or, equivalently, $K_{v}$, reduces as a result of the submergence of the backfill. 
f. This SSI analysis shows that in the case of a postconstruction rise in the groundwater level in the backfill, a rebound of the soil occurs. This results in a reduction in effective stress in the backfill and a reduction in the shear force $F_{v}$. This also occurred at Red River Lock No. 1 (Ebeling et al. 1993. or Ebeling and Mosher 1996).

g. During the postconstruction, partial submergence of the backfill to el 395 , the buoyancy forces act upward, unloading the backfill. This results in a reversal in the direction of the applied shear stress increment or, equivalently, unloading of both the new RCC lock-to-backfill interface elements and the existing lock concrete-to-backfill interface elements. Interface tests reported in Peterson et al. (1976) show that the interface elements follow a steeper shear stress versus relative shear displacement curve than that described by the "primary" hyperbolic loading curve. Incorporating this type of interface behavior in the SSI analysis of the new RCC McAlpine Lock wall is important to the accuracy of the computed results.

$h$. Appendix B reports on the errors related to using the "softer" primary hyperbolic curve for the interface elements during partial submergence of the backfill to el 395 compared to the results from using the more appropriate "stiffer" shear stress versus relative shear displacement curve. The most important error resulting from using a soft shear stress versus relative shear displacement curve during unloading for the interface elements is in the overprediction of the value for the effective normal stress computed below the heel of the new RCC lock wall.

\section{References}

Clough, G. W., and Duncan. J. M. (1969). "Finite element analyses of Port Allen and Old River Locks," Contract Report S-69-6, U.S. Army Engineer Waterways Experiment Station, Vicksburg, MS.

Duncan, J. M., Byrne, P., Wong, K. S., and Mabry, P. (1978). "Strength, stressstrain and bulk modulus parameters for finite element analyses of stresses and movements in soil masses," Report No. UCB/GT/78-02, College of Engineering, Office of Research Services, University of California, Berkeley, CA.

Ebeling, R. M., Clough, G. W., Duncan, J. M., and Brandon, T. L. (1992). "Methods of evaluating the stability and safety of gravity earth retaining structures founded on rock," Technical Report REMR-CS-29, U.S. Army Engineer Waterways Experiment Station, Vicksburg, MS.

Ebeling, R. M., Duncan, J. M., and Clough, G. W. (1990). "Methods of evaluating the stability and safety of gravity earth retaining structures founded on rock phase 2 study," Technical Report ITL-90-7, U.S. Army Engineer Waterways Experiment Station, Vicksburg, MS. 
Ebeling, R. M., and Mosher, R. L. (1996). "Red River U-Frame Lock No. 1 backfill-structure-foundation interaction," ASCE Journal of Geotechnical Engineering 122(3), pp 216-225.

Ebeling, R. M., Mosher, R. L., Abraham, K., and Peters, J. F. (1993). "Soilstructure interaction study of Red River Lock and Dam No. 1 subjected to sediment loading," Technical Report ITL-93-3, U.S. Army Engineer Waterways Experiment Station, Vicksburg, MS.

Ebeling, R. M., and Pace, M. E. (1996). "Uplift pressures resulting from flow along tapered rock joints," The REMR Bulletin, 13(1), 1-4, U.S. Army Engineer Waterways Experiment Station, Vicksburg, MS.

(1997). "Evaluating the stability of existing massive concrete gravity retaining structures founded on rock," Technical Report REMR-CS54, U.S. Army Engineer Waterways Experiment Station, Vicksburg, MS.

Ebeling, R. M., Peters, J. F., and Clough, G. W. (1990). "User's guide for the incremental construction soil-structure interaction program SOILSTRUCT," Technical Report ITL-90-6, U.S. Army Engineer Waterways Experiment Station, Vicksburg, MS.

Headquarters, Department of the Army. (1995). "Navigation Locks," Engineering Manual 1110-2-2602, Washington, DC.

Peterson, M., Kulhawy, F., Nucci, L., and Wasil, B. (1976). "Stress-deformation behavior of soil-concrete interfaces," Contract Report B-49 to Niagara Mohawk Power Corp., Dept. of Civil Engineering, Syracuse University, Syracuse, NY.

Regalado, L. R., Duncan, J. M., and Clough, G. W. (1992). "Finite element analyses of gravity earth retaining structures founded on soil," Contract report to the U.S. Army Eengineers Waterways Experiment Station, Vicksburg, MS. 


\section{Appendix A \\ Backfill Placement Analysis of Moist One-Dimensional Soil Column}

There are two major requirements for the assignment of material parameters in the complete soil-structure interaction analysis of the new roller-compacted concrete (RCC) McAlpine Lock wall using the backfill placement method that is incorporated in SOILSTRUCT-ALPHA. One requirement is that the stressstrain model for the soil representing the backfill be representative of the soil comprising the backfill. The second requirement is that the material properties assigned to the soil used to model the backfill possess an at-rest earth pressure coefficient equal to 0.44 (from Jaky's relationship for $K_{o}\left(=1\right.$ - $\left.\sin \phi^{\prime}\right)$ with $\phi^{\prime}$ equal to $34 \mathrm{deg}$ ). Calculations described in this appendix are used in the assignment of the value of the nominal Poisson's ratio for soil.

This appendix summarizes the results of the backfill placement analysis of the moist one-dimensional (1-D) soil column shown in Figure A1. Settlement of the soil column resulted from self-weight. Calculations are made using SOILSTRUCT-ALPHA.

Site-specific triaxial test data were unavailable for the new RCC lock wall backfill. Material parameters are assigned in the finite element analysis based on empirical correlations to the results for similar types of soils (and with the same density) for which hyperbolic stress-strain curve material parameters are available (e.g., Duncan et al. $1978^{1}$ ). The values listed in Table Al are the result of the evaluation made for this project.

A free-field soil column is constructed to be consistent with the layering used in the Figure 6 (main text) two-dimensional finite element model for the new backfill. The compression (settlement) of the Figure A1 1-D (constrained) soil column has the following characteristics:

1 References cited in this appendix are listed in the References at the end of the main text. 


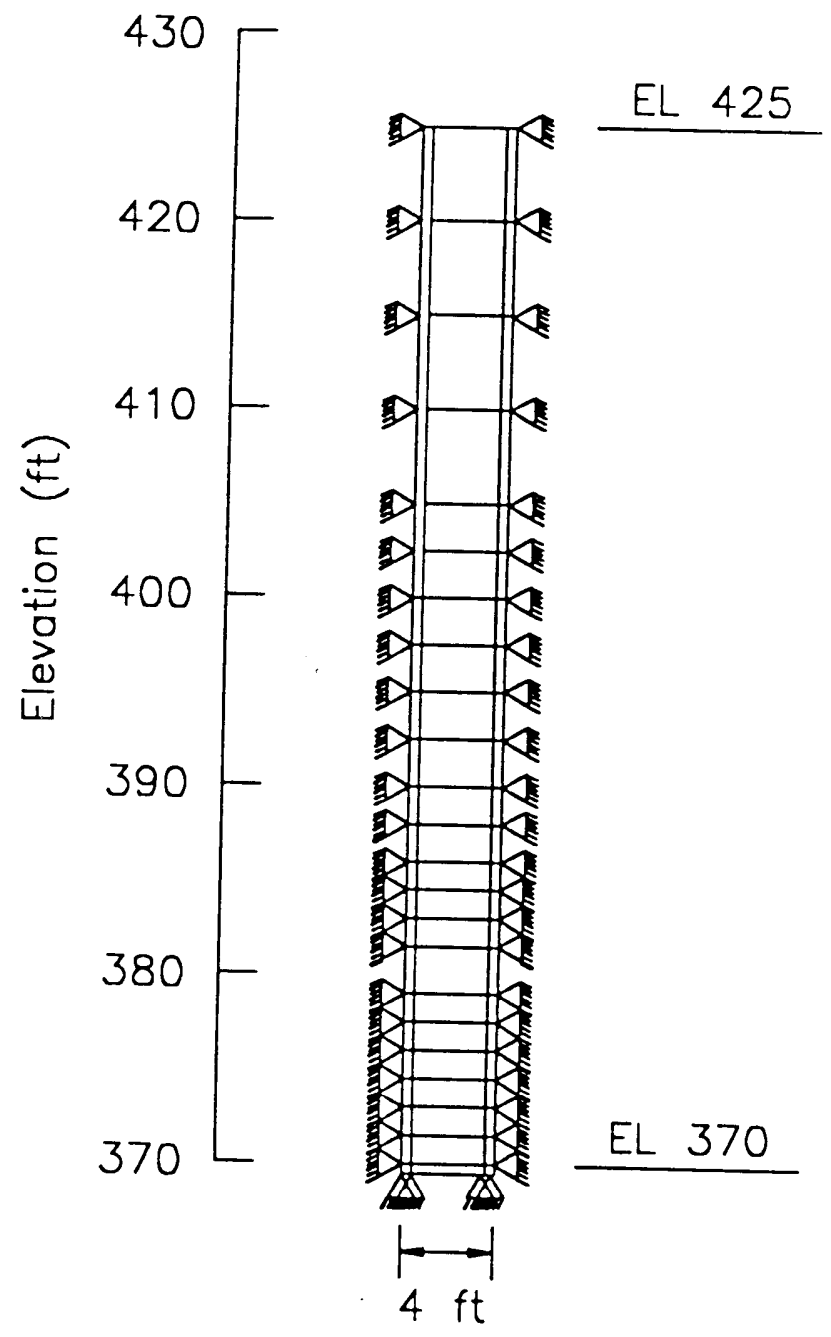

Figure A1. Finite element mesh for 1-D column analysis $(0.305 m=1 \mathrm{ft})$

a. At any given elevation, the soil layer possess uniform compressibility.

b. The horizontal strain $\epsilon_{\mathrm{x}}$ equals zero.

c. The vertical settlement at any given elevation is uniform. 


\section{Table A1}

Hyperbolic Stress-Strain and Strength Parameters for Moist Backfill $\left(0.157 \mathrm{kN} / \mathrm{m}^{3}=1\right.$ pcf, 47.88 $\mathrm{Pa}=1 \mathrm{psf}$ )

\begin{tabular}{|c|c|c|c|c|c|c|c|c|c|c|c|}
\hline \multirow[b]{2}{*}{ Backfill } & \multirow[b]{2}{*}{$\begin{array}{l}\text { Unit } \\
\text { Weight, pcf }\end{array}$} & \multicolumn{2}{|c|}{$\begin{array}{l}\text { Strength } \\
\text { Parameters }\end{array}$} & \multirow[b]{2}{*}{$K_{0}$} & \multicolumn{7}{|c|}{ Hyperbolic Parameters } \\
\hline & & $c^{\prime}, p s f$ & $\Phi^{\prime}$, deg & & K & n & $K_{U R}$ & $K_{\mathrm{B}}$ & m & $V_{\text {nom }}$ & $\mathbf{R}_{\mathrm{F}}$ \\
\hline $\begin{array}{l}\text { Moist } \\
\text { Granular } \\
\text { Backfill }\end{array}$ & 126 & 0 & 34 & 0.44 & 500 & 0.5 & 1,000 & 175 & 0.5 & 0.025 & 0.7 \\
\hline
\end{tabular}

Note:

$K_{o}$ by Jaky $=1-\sin \Phi^{\prime}$

Tangent Modulus, $E_{t}=E_{l}\left(1-R_{F} S L\right)^{2}$

Initial Modulus, $E_{1}=K P_{2}\left(\frac{\sigma_{3}^{\prime}}{P_{a}}\right)^{n}$

Stress Level, $S L=\left(\sigma_{1}-\sigma_{3}\right) /\left(\sigma_{1}-\sigma_{3}\right)_{\text {Fallure }}$

$\left(\sigma_{1}-\sigma_{3}\right)_{\text {Falure }}=\frac{2 c^{\prime} \cos \phi+2 \sigma_{3}^{\prime} \sin \phi}{1-\sin \phi}$

Unload-Reload Modulus, $E_{U R}=K_{U R} P_{a}\left(\frac{\sigma_{3}^{\prime}}{P_{a}}\right)^{n}$

Bulk Modulus, $B=\frac{E_{1}}{\left(3-6 v_{\text {nom }}\right)}$

Bulk Modulus, $B=K_{B} P_{a}\left(\frac{\sigma_{3}^{\prime}}{P_{a}}\right)^{m}$

$v_{\text {nom }}=$ Nominal value of Poisson's ratio

Poisson's ratio, $v=\frac{1}{2}\left[1-\left[\left(1-2 v_{\text {nom }}\right)\left(1-R_{F} S L\right)^{2}\right]\right]$

$P_{A}=$ atmospheric pressure

The backfill placement analysis of this 1-D column will serve as the model for a $\mathrm{K}_{\mathrm{o}}$ stress-state. The computed results are used to establish that the value assigned to the nominal Poisson's ratio in the SOILSTRUCT-ALPHA analysis is consistent with $\mathrm{K}_{\mathrm{o}}$ equal to 0.44 . 
Figure A1 shows the SOILSTRUCT-ALPHA finite element model of the 1-D soil column used in this appendix. The moist soil column is $55 \mathrm{ft}(16.76 \mathrm{~m})$ high. Water pressures are assumed equal to zero at the time of backfilling to elevation 425. ${ }^{\text {T }}$ These two assumptions are consistent with the initial load cases of the backfill placement analysis of the new RCC McAlpine lock wall, described in the main body of the report. The finite element mesh for the soil column comprises 22 soil layers. They range in thickness from $1.5 \mathrm{ft}(0.46 \mathrm{~m})$ thick at the base to 5 $\mathrm{ft}(1.5 \mathrm{~m})$ thick at the top of the column. The elevations of the nodes defining the soil elements in this figure were the same elevations as the nodes defining the new backfill in Figure 6 (see main text). Interface elements of approximately zero shear stiffness and very large normal stiffness are included along the vertical faces of the mesh shown in Figure A1 to take advantage of the postprocessing capability within SOILSTRUCT-ALPHA. SOILSTRUCT-ALPHA computes the horizontal and vertical resultant forces and their points of application (elevation) along specified regions of interface elements using the normal and shear stress data. The pair of 22 interface element columns delineate a single region within the backfill in this backfill placement analysis. These results expedite the calculation of the horizontal earth pressure coefficient $\mathrm{K}_{\mathrm{h}}$ (equivalent to an at-rest coefficient $\mathrm{K}_{\mathrm{o}}$ in the 1-D soil column) for the finite element analysis of the soil column.

Total (moist) unit weight equal to $126 \mathrm{pcf}\left(2,018.32 \mathrm{~kg} / \mathrm{cm}^{3}\right)$ is assigned to the soil. Material properties assigned to the hyperbolic stress-strain relationship for the soil elements are given in Table A1. The values for the parameters listed in this table are typical of dense, granular backfill. The material properties assigned to the interface elements are given in Table A2.

The backfill placement analysis of the Figure A1 soil column is conducted in 22 lifts or, equivalently, 22 load increments using SOILSTRUCT-ALPHA. The distributions of horizontal effective stress and vertical effective stress with elevation computed within the soil elements after placement of the final (22nd) lift are not shown. The shear stress $\tau_{x y}$ equals zero in all soil elements. The integral over the height of the soil column of the horizontal effective stresses $\sigma_{x}^{\prime}$, is equal to the horizontal effective force $F_{x}$. The horizontal effective force $F_{x}$, computed by SOILSTRUCT-ALPHA using the normal effective stresses within the interface elements, equals $84,038 \mathrm{lb}$ per $\mathrm{ft}$ of width $(1,226.4 \mathrm{kN}$ per $\mathrm{m})$. The value of the horizontal earth pressure coefficient $K_{h}$ is computed using Equation 1 in the main text.

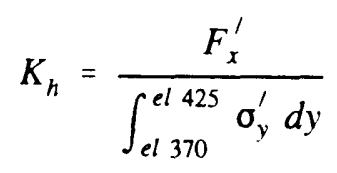

1 All elevations (el) cited herein are in feet referenced to the National Geodetic Vertical Datum. 


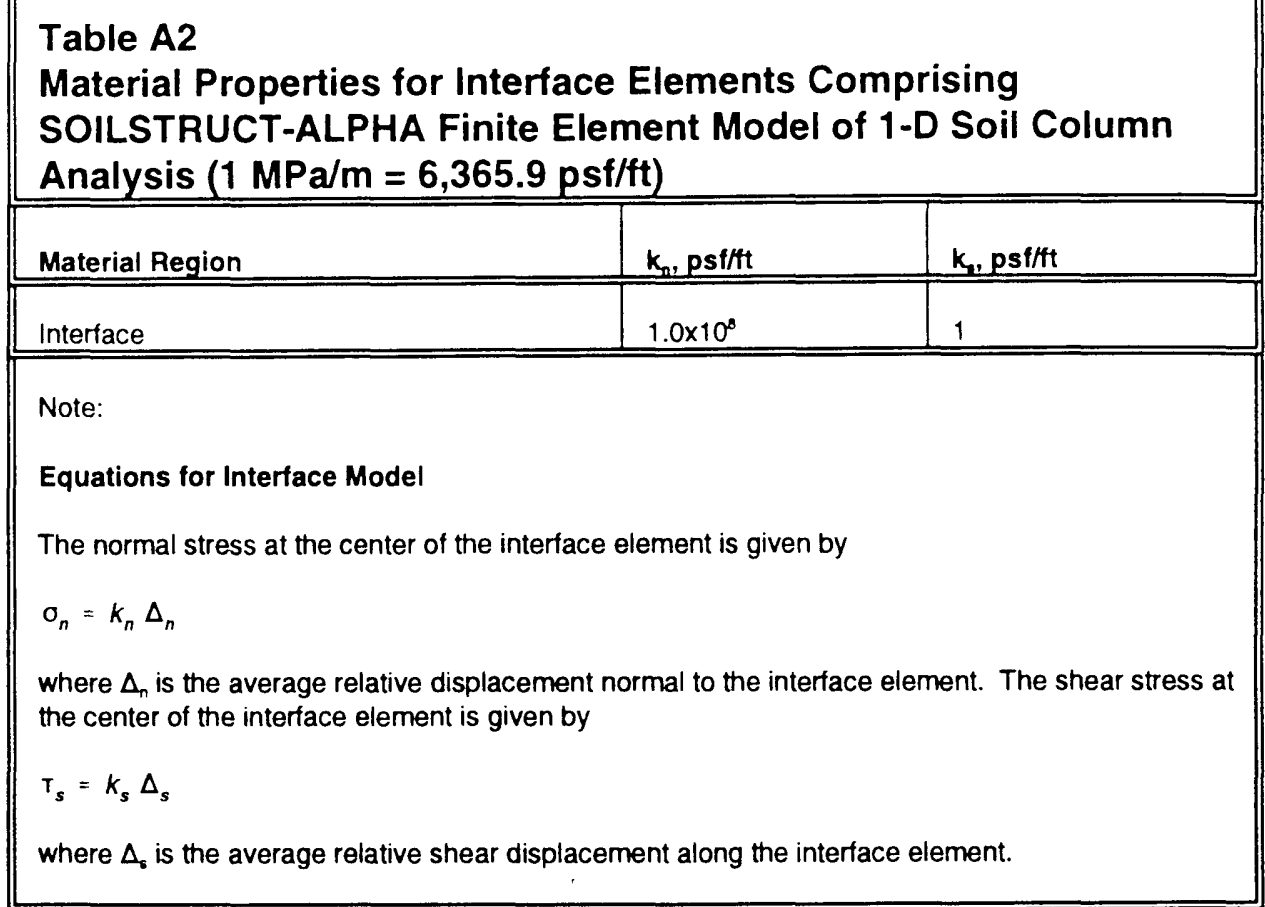

The denominator, designated as the Effective Overburden in this report, is the integral of the vertical effective stress distribution for the $55-\mathrm{ft}-(16.76 \mathrm{~m})$ high soil column (not shown). With the Effective Overburden computed using Equation 3 (see main text) equal to $190,575 \mathrm{lb}$ per $\mathrm{ft}$ run of wall $(2,781.2 \mathrm{kN}$ per $\mathrm{m}), \mathrm{K}_{\mathrm{h}}$ is equal to 0.44 . With the lateral strain $\epsilon_{\mathrm{x}}$ equal to zero along the soil column, $K_{h}$ (Equation 2 in main text) is equivalent to $K_{0}$.

One of the material parameters assigned to the soil is the value for the nominal Poisson's ratio. This nominal Poisson's ratio $v_{\text {nom }}$ used in SOILSTRUCT-ALPHA differs from the traditional strength of materials definition of Poisson's ratio $U$. The complete derivation of $v_{\text {nom }}$ and its corresponding value of $v$ is given in Appendix C of Ebeling and Pace (1997). Using the relationship

$$
K_{o}=\frac{1-\left(1-2 v_{n o m}\right)\left[1-R_{F} \frac{(1-\sin \phi)\left(1-K_{o}\right)}{2 K_{o} \sin \phi}\right]^{2}}{1+\left(1-2 v_{n o m}\right)\left[1-R_{F} \frac{(1-\sin \phi)\left(1-K_{o}\right)}{2 K_{o} \sin \phi}\right]^{2}}
$$

$v_{\text {nom }}$ is computed equal to 0.025 for the Table Al material properties with $\mathrm{K}_{\mathrm{o}}$ equal to 0.436 or 0.44 . The value for $K_{o}$ from the results of the SOILSTRUCTALPHA analysis of the soil column are consistent with the results from using Equation Al. 


$$
v=\frac{1-\left(1-2 v_{n o m}\right) *\left(1-R_{F} S L\right)^{2}}{2}
$$

with $R_{F}=0.7, S L=0.51$, and $v_{\text {nom }}=0.025$ results in $v$ equal to 0.30 . SL is computed using SOILSTRUCT-ALPHA to be 0.51 , on average, for the 22 soil elements of Figure A1.

In 1978, a bulk modulus formulation was developed by Duncan and his colleagues for use in SOILSTRUCT (Ebeling, Peters, and Clough 1992). This formulation is given in Table B 1 in this report. The bulk modulus is intended to replace Poisson's ratio as the second elastic parameter. Calculation of corresponding (and equivalent) value of the bulk modulus number $\mathrm{K}_{\mathrm{b}}$ for the bulk modulus formulation is made using Equation $\mathrm{C} 10$ in Appendix $\mathrm{C}$ of Ebeling and Pace (1997). With $K=500, v_{\text {nom }}=0.025$, and the bulk modulus exponent $\mathrm{m}=\mathrm{n}=$ $0.5, \mathrm{~K}_{\mathrm{b}}$ equals 175 . 


\section{Appendix B}

\section{Comparison of SOILSTRUCT- ALPHA Results After}

Backfilling to Elevation 425 and Partial Submergence of Backfill to Elevation 395 for Two Interface Shear Stiffness Models

During postconstruction, partial submergence of the backfill to elevation (el) $395^{1}$ (identified as load cases 25 through 38 in Table 1 (see main text)), the buoyancy forces act upward, unloading the backfill. This results in a reversal in the direction of the applied shear stress increment or, equivalently, unloading of both the new roller-compacted concrete (RCC) lock-to-backfill interface elements and the existing lock concrete-to-backfill interface elements. Interface tests reported in Peterson et al. $(1976)^{2}$ show that the interface elements follow a steeper shear-stress-versus-relative-shear-displacement curve than that described by the "primary" hyperbolic loading curve (the tangent shear stiffness $\mathrm{k}_{\mathrm{st}}=\mathrm{k}_{\mathrm{si}}[1$ $\mathrm{R}_{\mathrm{f}} \mathrm{SL}_{\mathrm{l}} \mathrm{l}^{2}$ ). To model this "stiffer" behavior, the interface model parameter $\mathrm{R}_{\mathrm{fi}}$ is set equal to zero for these interface elements during unloading for the results reported in the main body of the report. Figure Bla illustrates the concept behind the stiff unload interface model. This appendix compares these results with those in which the "primary" hyperbolic loading curve is followed during partial submergence of the backfill to el 395 . That is, the "shear softening" is maintained during unloading (i.e., the term $\mathrm{R}_{\mathrm{fi}}$ is maintained at its Table 5 (in main report) value for all interface regions). This soft unload interface model is illustrated in Figure B1b.

1 All elevations (el) cited herein are in feet referenced to the National Geodetic Vertical Datum.

2 References cited in this appendix are listed in the References at the end of main text. 


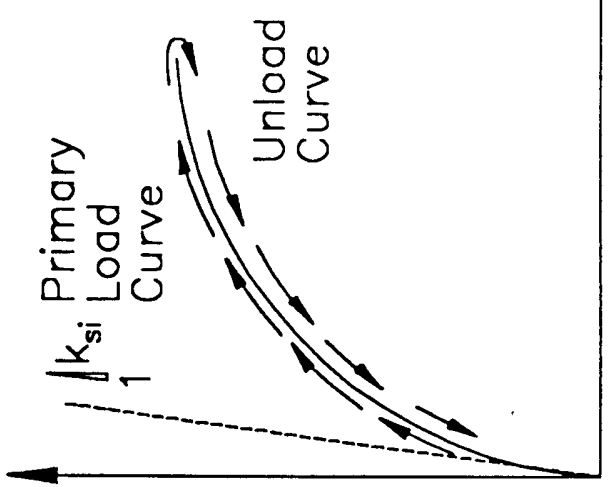

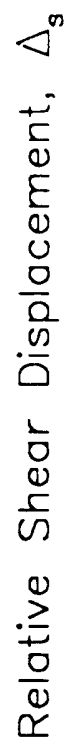

$\perp$ 'SS2ג7S دD24S

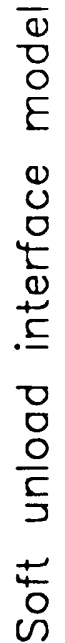

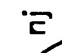

o b. $^{\circ}$

$r^{3}$

$x$

॥

$x^{\bar{m}}$

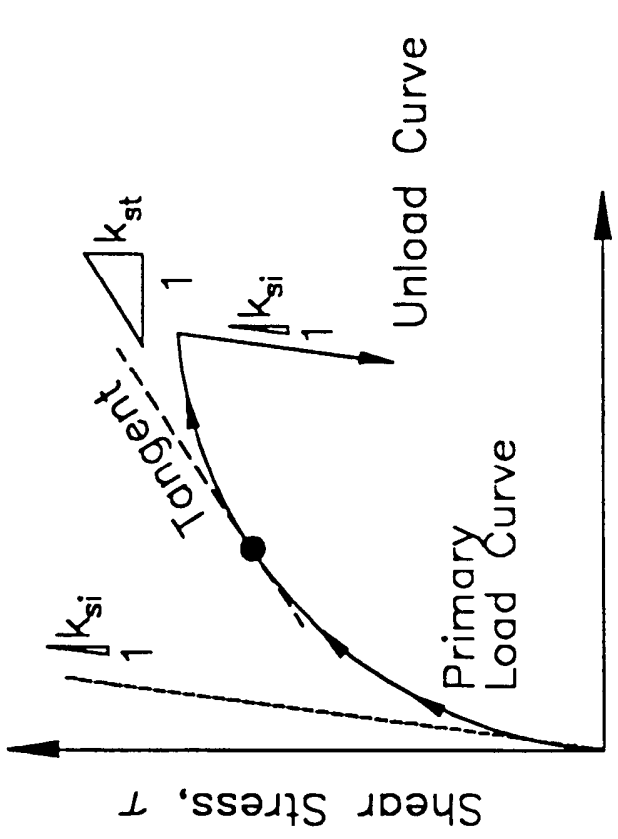

$\Delta^{\infty}$

茂

离

ठ जे

음

$\frac{.09}{0}$

¿̀

$\frac{d}{n}$

t)

.

믕

5 i

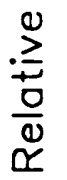

$\leftleftarrows \quad 11$

它 $x^{5}$

ธ

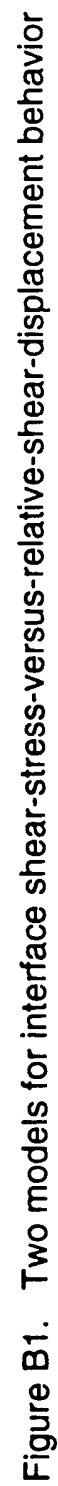


Figures B2 and B3 show the resulting effective normal and shear stress distributions along the RCC lock-to-limestone interface after backfilling to el 425 and partial submergence of the backfill to el 395 (load case 38) for the "stiff" and "soft" interface shear-stiffness-versus-relative-shear-displacement models used during unloading (load cases 25 through 38). Both effective normal and shear stress distributions are nonlinear. As anticipated, the greatest values of stress are computed below the toe of the new RCC lock $(x=0 \mathrm{ft}(\mathrm{m}))$ because the greatest concrete mass is concentrated above this region and because of the overturning moment about the toe resulting from the $55 \mathrm{ft}(16.76 \mathrm{~m})$ of backfill. The effective normal stress below the heel of the new RCC lock $(x=47 \mathrm{ft}(14.33 \mathrm{~m}))$ is equal to $0 \mathrm{psf}(\mathrm{kPa})$ and $307 \mathrm{psf}(14.7 \mathrm{kPa})$ for the stiff and soft interface models used during unloading, respectively. Full base area contact is maintained in both analyses.

Table $\mathrm{B} 1$ summarizes the results of calculations made to determine the resultant horizontal effective force $F_{\mathrm{x}}$ and horizontal earth pressure coefficient $\mathrm{K}_{\mathrm{h}}$ at section A-A. The resultant horizontal effective force of the Figure 14 (see main text) distribution of $\sigma_{x}^{\prime}, F_{x}$, is equal to $79,102 \mathrm{lb}$ per $\mathrm{ft}$ run of wall $(1,154.4 \mathrm{kN}$ per $\mathrm{m})$ and acts at el $390.99\left(=0.38 \mathrm{H}_{\text {backfill }}\right)$ along section A-A when a stiff interface shear stiffness model is used. The corresponding value for the horizontal earth pressure coefficient $K_{t}$ is 0.459 (Figure 17 in main text). The resultant horizontal effective force of the distribution of $\sigma_{x}^{\prime}$ (not shown) is made for the analysis using a soft interface shear stiffness model during unloading and $F_{x}$, is computed equal to $77,490 \mathrm{lb}$ per $\mathrm{ft}$ run of wall $(1,130.9 \mathrm{kN}$ per $\mathrm{m})$ and acts at el $391.15\left(=0.38 \mathrm{H}_{\text {backfill }}\right)$ along section $\mathrm{A}-\mathrm{A}$. The corresponding value for the horizontal earth pressure coefficient $\mathrm{K}_{\mathrm{h}}$ is 0.45 . The results from these two SOILSTRUCT-ALPHA analyses show that effect of the type of interface shear stiffness model used during partial submergence or, equivalently, unloading, of the backfill to be minor in terms of the computed values for $F_{x}$ and $K_{h}$ along section A-A.

Similarly, Table B1 summarizes the results of calculations made to determine the resultant vertical shear force $F_{v}$ and vertical earth pressure coefficient $K_{v}$ at section A-A. The resultant vertical shear force of the Figure 15 (see main text) distribution of $\tau_{x y}, F_{v}$, is equal to $6,775 \mathrm{lb}$ per ft run of wall $(98.9 \mathrm{kN}$ per m) along section $\mathrm{A}-\mathrm{A}$ when a stiff interface shear stiffness model is used. The corresponding, value for the vertical earth pressure coefficient $\mathrm{K}_{\mathrm{v}}$ is 0.039 (Figure 18 in main text). The resultant vertical shear of the distribution of $\tau_{x y}$ (not shown) is made for the analysis using a soft interface shear stiffness model during unloading, and $F_{v}$ is computed equal to $8,900 \mathrm{lb}$ per $\mathrm{ft}$ run of wall $(129.9 \mathrm{kN}$ per $\mathrm{m})$ along section A-A. The corresponding value for the horizontal earth pressure coefficient $\mathrm{K}_{\mathrm{v}}$ is 0.052 . The results from these two SOILSTRUCT-ALPHA analyses show that the effect of the type of interface shear stiffness model used during partial submergence or, equivalently, unloading, of the backfill impacts the computed values for $F_{v}$ and $K_{v}$ along section $A-A$, as anticipated. The soft interface shear stiffness model overpredicts the values of $F_{v}$ and $K_{v}$ for section A-A by 31 percent. This error is unconservative since $F_{v}$ is a stabilizing force. 


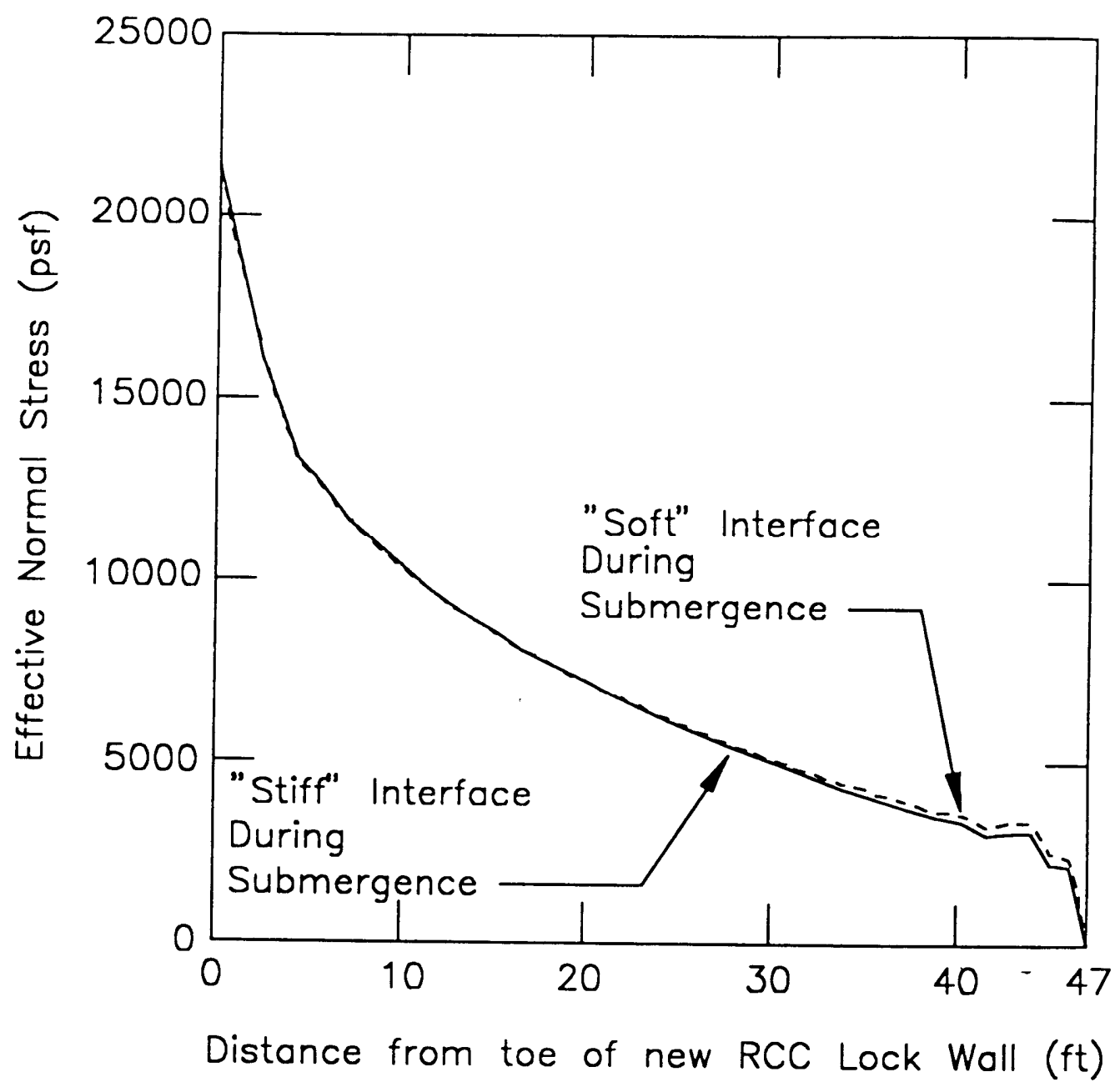

Figure B2. Effective normal stress distributions along the base of new RCC lock wall - partial submergence to el $395(0.305 \mathrm{~m}=1 \mathrm{ft}, 47.88 \mathrm{~Pa}=1 \mathrm{psf})$

Table B2 summarizes the resultant forces and their points of application on the free body of the new RCC lock wall through which imaginary section(s) shown in Figure B4 are made. These resultant forces and their points of application are computed by SOILSTRUCT-ALPHA after backfilling to el 425 and after partial submergence of the backfill to el 395 (load case 38). The Table $\mathrm{B} 2$ results show that the shear force $\mathrm{F}_{\mathrm{s}}$ along the back of the new $\mathrm{RCC}$ lock wall is increased by 4.9 percent with the use of the soft interface shear stiffness model during unloading (load cases 25 through 38 ). The downdrag force $F_{s}$ is a stabilizing force, acting in the direction of the heel of the wall. More importantly, greater effective normal stresses are computed below the heel of the new RCC lock when the soft interface shear stiffness model is used during unloading (refer to Figure B2). 


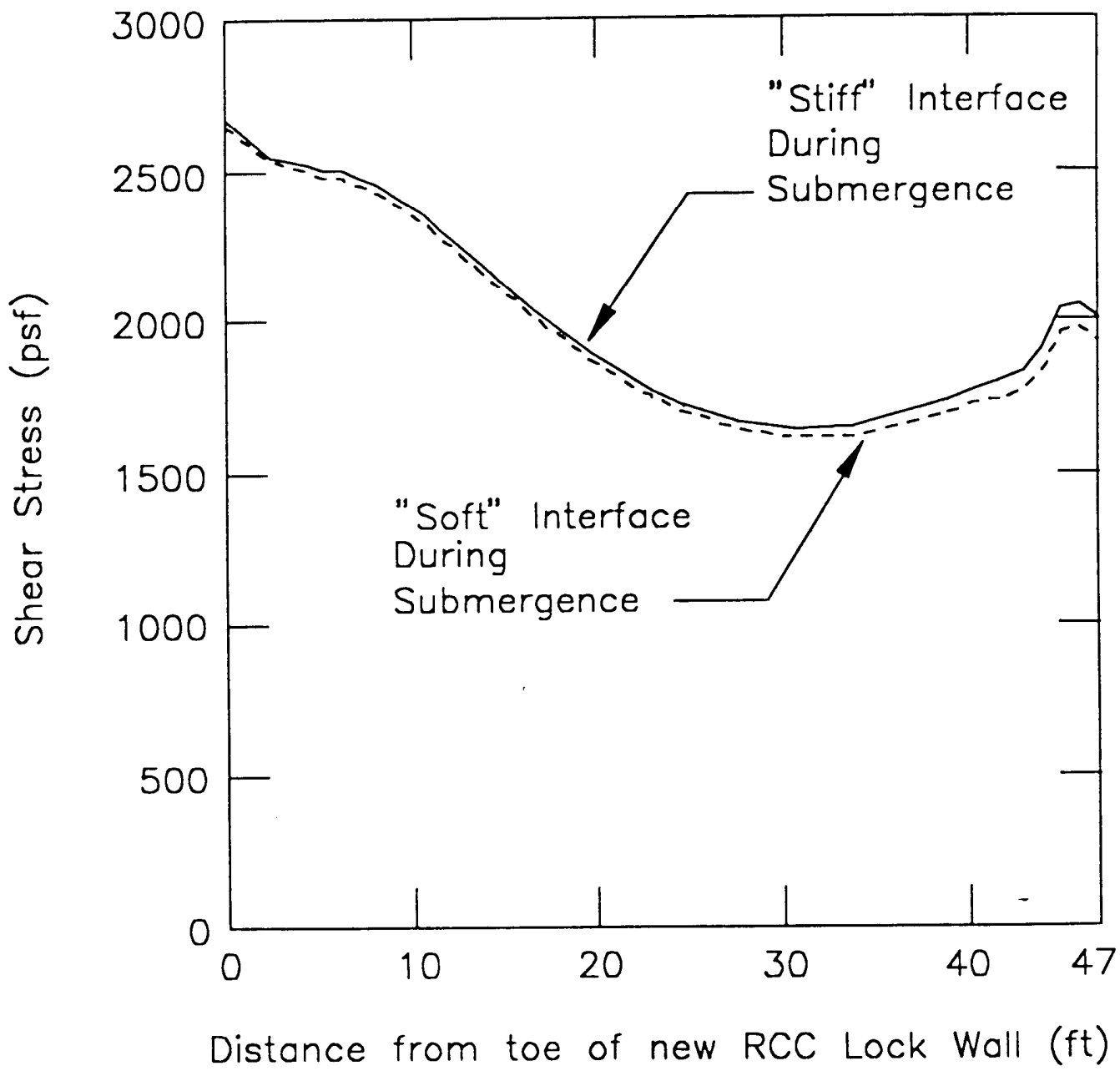

Figure B3. Shear stress distributions along base of new RCC lock wall - partial submergence to el $395(0.305 \mathrm{~m}=1 \mathrm{ft}, 47.88 \mathrm{~Pa}=1 \mathrm{psf})$

\section{Table B1}

Summary of SOILSTRUCT-ALPHA Results Along Section A-A for "Soft" and "Stiff" Interface Shear Stiffnesses During Partial Submergence of Backfill to El 395 (Load Case 38) (14.594 N per $m=1 \mathrm{lb}$ per $\mathrm{ft}$ run of wall)

\begin{tabular}{|c|c|c|c|c|c|}
\hline $\begin{array}{l}k_{\text {w }} \text { During } \\
\text { Unloading }\end{array}$ & $\begin{array}{l}\text { Effective } \\
\text { Overburden, lb per } \\
\text { ft run of wall }\end{array}$ & $\begin{array}{l}F_{x} ;, l b \text { per } f t \\
\text { run of wall }\end{array}$ & $\begin{array}{l}F_{v}, \text { lb per } f t \\
\text { run of wall }\end{array}$ & $K_{n}$ & $K_{v}$ \\
\hline "stiff" with $R_{1}=0$ & 172,325 & 79,102 & 6,775 & 0.459 & 0.039 \\
\hline $\begin{array}{l}\text { "soft" hyperbolic } \\
\text { primary curve }\end{array}$ & 172,325 & 77,490 & 8,900 & 0.450 & 0.052 \\
\hline
\end{tabular}




\section{Table B2}

Summary of SOILSTRUCT-ALPHA Results After Submergence to EI 395 (Load Case 38) for "Soft" and "Stiff" Interface Shear Stiffnesses During Partial Submergence of Backfill (14.594 N per $\mathrm{m}=1 \mathrm{lb}$ per $\mathrm{ft}$ run of wall, $0.305 \mathrm{~m}=1 \mathrm{ft}$ )

\begin{tabular}{|c|c|c|c|c|c|c|c|c|c|}
\hline \multicolumn{10}{|c|}{ Resultant Normal and Shear Forces } \\
\hline $\begin{array}{l}k_{n}, \text { During } \\
\text { Unloading }\end{array}$ & $\begin{array}{l}F_{\text {., }} \text { ib per } \mathrm{At} \\
\text { run of wall }\end{array}$ & $\begin{array}{l}F_{n}, \text { lb per } \\
f t \text { run of } \\
\text { wall }\end{array}$ & $I_{f n}, f t$ & $I_{F N} / L$ & $\begin{array}{l}\delta_{\text {mobb }} \\
\text { deg }\end{array}$ & $T, \mathbf{l b}$ & $\mathbf{N}^{\prime}, \mathbf{l b}$ & $x_{N}, f t$ & $x_{w} / B$ \\
\hline "Stiff" with $\mathrm{R}_{11}=0$ & 55,404 & 128,436 & 23.32 & 0.36 & 23.33 & 93,820 & 347,902 & 16.18 & 0.34 \\
\hline $\begin{array}{l}\text { "Soft" Hyperbolic } \\
\text { Primary Curve }\end{array}$ & 58,098 & 128,348 & 23.17 & 0.36 & 24.35 & 92,298 & 350,127 & 16.44 & 0.35 \\
\hline \multicolumn{10}{|c|}{ Resultant Water Pressure Forces } \\
\hline Load Case & $\begin{array}{l}U_{\text {beno, }} \text { ib per } \\
\mathrm{ft} \text { run of } \\
\text { wall }\end{array}$ & $x_{\text {uben, }}, f t$ & $\frac{x_{\text {nowere }}}{B}$ & $\begin{array}{l}U_{\text {tromt }} \\
\text { Ib per } \\
\text { ft run } \\
\text { of } \\
\text { wall }\end{array}$ & $h_{\text {Utrome }}, f t$ & $\begin{array}{l}\mathrm{U}_{\text {beck }} \text { ib } \\
\text { per } \mathrm{ft} \\
\text { run of } \\
\text { wall }\end{array}$ & $\mathrm{I}_{\text {Uoeck }}, \mathrm{ft}$ & & \\
\hline 38 & 66,435 & 25.97 & 0.55 & $\begin{array}{l}5,272 \\
8 \\
\end{array}$ & 4.33 & 23,113 & 9.88 & & \\
\hline \multicolumn{10}{|c|}{$\begin{array}{l}\text { Note: } \\
\text { where } B=47 \mathrm{ft}, L=65.19 \mathrm{ft} \text {, and } \tan \left(\delta_{m o b}\right)=\frac{F_{s}}{F_{n}^{\prime}}\end{array}$} \\
\hline
\end{tabular}

The values of stress level, $\mathrm{Sl}_{i}$, computed within the interface elements change with the submergence of the backfill. During the postconstruction, partial submergence of the backfill to el 395 , the buoyancy forces act upward unloading the backfill. This results in a reversal in the direction of the applied shear stress increment or, equivalently, unloading of the 22 new RCC lock-to-backfill interface elements. This is accompanied by a reduction in the effective stresses normal to the back of the lock wall within those interface elements located below the water table (el 395). At the end of backfilling to el 425 (load case 24), the average value of stress level $S L_{1}$ for the interface elements equals 0.70 . After partial submergence of the backfill to el 395 (load case 38), the results of the SOILSTRUCT-ALPHA interaction analysis using the stiffer inter-face model during unloading (Figure B 1a) shows that the average reduction in stress level SL, for the interface elements is 8.6 percent (ranging from zero to a 23-percent reduction). Changes in both shear and normal effective stresses during submergence account for the reduction in values of the stress levels $S L_{1}$ for the 22 interface elements. 


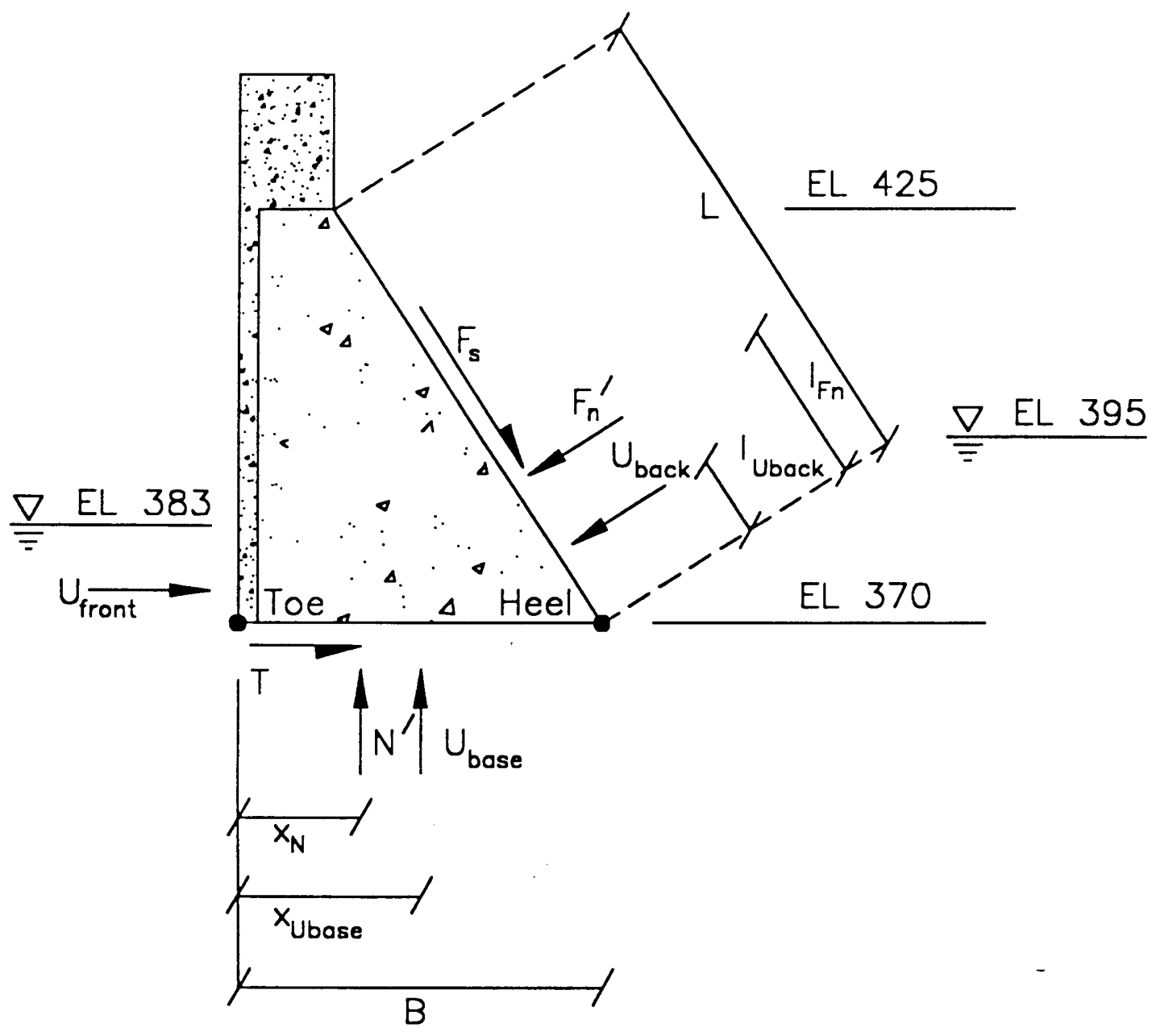

Figure B4. Planes along surfaces of the new RCC lock on which resultant forces are computed - submerged to el $396(0.305 \mathrm{~m}=1 \mathrm{ft})$ 


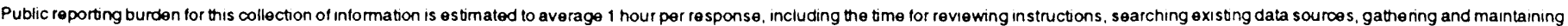

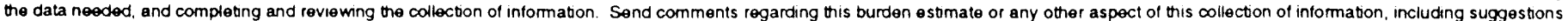

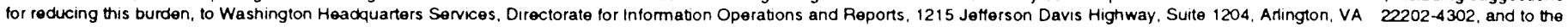
Office of Management and Budget. Paperwork Reduction Project (0704-0188). Washington, DC 20503.
1. AGENCY USE ONLY (Leave blank)
2. REPORT DATE
3. REPORT TYPE AND DATES COVERED
July 1997
Final report

4. TitLe and subtitle

Soil-Structure-Foundation Interaction Analysis of New Roller-Compacted

Concrete North Lock Wall at McAlpine Locks

6. AUTHOR(S)

Robert M. Ebeling, Ronald E. Wahl

7. PERforming organization name(S) AND ADDRESS(ES)

U.S. Army Engineer Waterways Experiment Station

3909 Halls Ferry Road

Vicksburg, MS 39180-6199

8. PERFORMING ORGANIZATION REPORT NUMBER

Technical Report ITL-97-5

9. SPONSORINGMONITORING AGENCY NAME(S) AND ADDRESS(ES)

U.S. Army Engineer District, Louisville

10. SPONSORINGMONITORING AGENCY REPORT NUMBER

P.O. Box 59

Louisville, KY 40201-0059

\section{SUPPLEMENTARY NOTES}

Available from National Technical Information Service, 5285 Port Royal Road, Springfield, VA 22161.

12a. DISTRIBUTION/AVAILABILITY STATEMENT

Approved for public release; distribution is unlimited.

12b. DISTRIBUTION CODE

13. ABSTRACT (Maximum 200 words)

A new lock is to be constructed at the McAlpine Locks on the Ohio River at Louisville, KY. The new lock chamber will be defined by rock-founded, gravity, earth-retaining monoliths. One of the alternatives is to construct the walls using roller-compacted concrete (RCC) with a concrete facing, with the culverts located in the floor of the lock chamber.

The principal objective of this study is to assess the soil-to-structure-to-foundation interactions of a typical RCC lock wall two-dimensional section. Due to the nature of the problem, the conventional analysis techniques, which are based upon the equations of equilibrium and assumed stress distributions made along imaginary sections, did not provide sufficient information to satisfactorily evaluate the performance of this structure with regard to its interaction with the rock foundation and soil backfill. The general-purpose, nonlinear, incremental construction, finite element computer program, SOILSTRUCT-ALPHA is used to analyze the complex interactions among the lock, the backfill, and the foundation rock strata

The analysis is accomplished in three phases. The first phase of the analysis introduces the self-weight of the existing locks and existing backfill to the shale and limestone foundation. The second phase models the incremental construction of the RCC lock wall and the incremental placement of the (moist) backfill behind the wall. The third and final phase of the soil-structure interaction analysis models the postconstruction, partial submergence of the site. The complete soil-structure-rock foundation

(Continued)

14. SUBJECT TERMS

McAlpine Lock

Roller-compacted concrete

SOILSTRUCT-ALPHA
15. NUMBER OF PAGES

62

16. PRICE CODE
17. SECURITY CLASSIFICATION 18 . SECURITY CLASSIFICATION OF REPORT

UNCLASSIFIED
OF THIS PAGE

UNCLASSIFIED 
13. (Concluded).

interaction analysis of the north wall section of the new McAlpine Lock is modeled using 38 stages of loading in the SOILSTRUCT-ALPHA analysis. The results of this analysis are described in detail in this report. 